\title{
Postnatal Development and Plasticity of Corticocortical Projections from Area 17 to Area 18 in the Cat's Visual Cortex
}

\author{
David J. Price, ${ }^{1}$ Jose Manuel R. Ferrer, ${ }^{2, a}$ Colin Blakemore, ${ }^{2}$ and Nobuo Kato ${ }^{2, b}$ \\ 'Department of Physiology, University Medical School, Edinburgh EH8 9AG, United Kingdom and 2University Laboratory \\ of Physiology, Oxford OX1 3PT, United Kingdom
}

\begin{abstract}
We used retrogradely transported fluorescent tracers to study the development of projections from area 17 to area 18 in normal and monocularly deprived kittens. In newborn animals, cells in area 17 that were labeled from small, discrete injections in area 18 were concentrated around the retinotopically corresponding zone, but distributed with lower density over a very wide surrounding area. Hence, the total convergence and divergence of the projection were initially enormous, but they decreased dramatically, mainly during the first postnatal month, through elimination of the sparse, widespread distribution of projections. Injections of two different tracers close together in area 18 produced very few double-labeled cells in area 17 at any age, implying that most individual axons arborize over very small territories even at birth. In normal kittens the peak density of association cells in the upper layers, corrected for the overall expansion of the cortex, doubled over the first postnatal month and then declined gradually over the following several months, presumably because of continuing selection and elimination.
\end{abstract}

As shown in previous work (Price and Blakemore, 1985a), area 17 to 18 cells in newborn kittens were dlstrlbuted in two continuous bands in supragranular and infragranular layers. During normal maturation, elimination of projections results in the formation of distinct clusters; these lie preferentially in the upper layers above patches of ipsilateral eye input to layer 4 (Price et al., 1994). Monocular deprivation, which causes the terminal patches representing the deprived eye to become much smaller than normal, did not stop the normal decrease in overall convergence/divergence or the appearance of clusters of association cells, but the clusters were distinctly larger than normal in both hemispheres. Monocular deprivation also prevented the nor-

Received March 5, 1993; revised Oct. 18, 1993; accepted Oct. 26, 1993.

J.M.R.F. was a Luis Manuel Foundation Fellow, D.J.P. was a Beit Memorial Research Fellow, and N.K. was funded by the Japanese Monbushoh and The Wellcome Trust. The research was funded by grants from the Medical Research Council, The Wellcome Trust, The British Council, a European Network grant from the McDonnell-Pew Centre for Cognitive Neuroscience, Oxford, and DGICYT-PM91-0109. We thank Damira Caric for contributing to the experimental work, Pat Cordery and Katy Gillies for histological assistance, and Geoffrey Goodhill and Ashley Lotto for advice on mathematical analysis and computer programming.

Correspondence should be addressed to Dr. D. J. Price, Department of Physiology, University Medical School, Teviot Place, Edinburgh EH8 9AG, UK.

^Present address: Department of Physiology, Faculty of Medicine, University of Granada, Granada 18012, Spain.

'Present address: Department of Integrative Brain Science, Faculty of Medicine Kyoto University, 606 Kyoto, Japan.

Copyright (C) 1994 Society for Neuroscience $0270-6474 / 94 / 142747-16 \$ 05.00 / 0$ mal reduction in density of association cells within clusters after 1 month of age. Comparison with results from binocularly deprived animals, where clusters also form but association cell density is low, suggests that the size of clusters and the density of association cells retained depend on the overall level of cortical activity.

[Key words: visual cortex, area 17, area 18, corticocortical connections, development, monocular deprivation, plasticity, retrograde tracing, convergence, divergence, exuberant projection]

In normal adult cats, the projection from area 17 of the visual cortex to area 18 arises in a patchy fashion, from distinct clusters of neurons lying mainly in the superficial layers (Gilbert and Kelly, 1975; Albus and Meyer, 1981; Bullier et al., 1984b; Symonds and Rosenquist, 1984; Price and Blakemore, 1985a,b; Ferrer et al., 1988, 1992; Gilbert and Wiesel, 1989; Price et al., $1992,1994)$. Clusters of association cells in area 17 tend to lie over regions that receive input from both eyes and to avoid zones of pure contralateral input; neurons recorded within these association clusters are usually highly binocular (Price et al., 1994). Despite divergence of the area 17 to 18 projection in the adult cat, most individual association axons appear to terminate over quite small territories, probably smaller than $100 \mu \mathrm{m}$ across, within the overall region of divergence (Ferrer et al., 1988).

Price and Blakemore (1985a) have shown that this projection undergoes a major reorganization postnatally. Immediately after birth, association cells in area 17 that project to area 18 are distributed in two continuous bands, one lying in the superficial layers and the other in the deep layers, neither exhibiting any obvious periodic variation in cell density. By about 3 weeks of age the aberrant dense infragranular projection has largely disappeared, probably mainly through cell death, and the remaining association cells in the superficial layers have assumed their characteristic clustered appearance, through the withdrawal from area 18 of the axons of cells lying between the remaining clusters, without the death of those cells (Price and Blakemore, 1985b). We were interested to know how the distribution of individual association axons and their overall convergence and divergence change as this radical reorganization of the projection occurs. In view of the fact that the clumps of association cells, which emerge through elimination of projections from the intercluster zones, tend to lie selectively over regions receiving direct thalamic input from both eyes (Price et al., 1994), we were especially interested in the possibility that the process of cluster formation might be modified by monocular deprivation of vision, which changes the pattern of segregation of ipsilateral and contralateral axons innervating area 17. 
Table 1. Animals used in this study

$\begin{array}{lccl}\text { Animal } & \text { Age (d) } & & \text { Dyes injected } \\ \text { code } & \text { Injected } & \text { Perfused } & \\ \text { into area 18 }\end{array}$

Adult cats were 4 years old, and were perfused $5 \mathrm{~d}$ after injection $(+5)$. In animal N16, two pairs of injections were made in one hemisphere, one just anterior to AP0, the other more rostral; the two pairs were separated by $8 \mathrm{~mm}$ of unstained cortex. In MD1, a close pair of injections was made in each hemisphere (just anterior to AP0 on the left and further rostral on the right); in MD2 and MD3 an injection of DY was made in each hemisphere (near APO on the left and farther rostral on the right). DY, diamidino yellow; FB, fast blue.

\section{Materials and Methods}

Animals. All the animals were obtained from an isolated, pathogen-free breeding colony in the laboratory. Successful experiments were carried out on 17 normal kittens aged between 2 and $143 \mathrm{~d}$ (on the day of injection), a normal adult cat (4 years), and on six monocularly deprived (MD) cats, aged $82 \mathrm{~d}$ to adult. Full histories of the animals are listed in Table 1. In addition, data from nine other normal adult cats are included where indicated in Results; these cases have been described before (Ferrer et al., 1988)

Monocular deprivation. Standard methods were used to close one eye (Blakemore and Van Sluyters, 1975), before the time of natural eye opening (between 4 and $7 \mathrm{~d}$ of age). Kittens were fully anesthetized with ketamine hydrochloride $\left(22 \mathrm{mg} \cdot \mathrm{kg}^{-1}\right.$, i.m.) and the conjunctivae and lids of one eye were sutured separately. After recovery, kittens were returned to their mothers. This procedure was rapid, and appeared to cause little or no distress to the animals. Infection was prevented by the administration of Streptopen $(0.1 \mathrm{ml}, \mathrm{i} . \mathrm{m}$.) and there were no postoperative complications.

Injection of retrograde tracers. For injection of tracers, anesthesia was induced with ketamine $\left(22 \mathrm{mg} \cdot \mathrm{kg}^{-1}, \mathrm{i} . \mathrm{m}\right.$.) and maintained throughout with alphaxalone-alphadolone (Saffan, Glaxo) intravenously as required (up to about $0.03 \mathrm{ml} \cdot \mathrm{min}^{-1}$ in older animals; less in young kittens). The electrocardiogram was monitored continuously. Once full surgical anesthesia had been achieved, the animal was placed in a purpose-built stereotaxic frame (Eldridge, 1979). Tracer was injected into area 18 , by means of a pulsatile pressure system, from a glass micropipette (tip diameter $\sim 50 \mu \mathrm{m}$ ) introduced through a small craniotomy and durotomy into the lateral gyrus. In all animals, injections were into the rostral half of area 18 where it occupies the crest of the gyrus. In most cases, only one hemisphere was injected, about $1 \mathrm{~mm}$ rostral to the level of the coronal plane running through the external auditory meatuses (anteroposterior zero, AP0); in one cat (N16), two pairs of injections were made in the same hemisphere (see below). In three of the MD animals (MD1-MD3), injections were made bilaterally (see below). After injection, the wound was sutured and the animal recovered. Kittens were returned to their mothers, and postoperative infection was prevented with Streptopen $(0.1 \mathrm{ml}$, i.m.).

Either diamidino yellow (DY) or fast blue (FB) was injected with the tip of the capillary at a depth below the pial surface roughly equal to half the thickness of the cortex $(0.5-1.0 \mathrm{~mm}$, depending on the age of the animal). Each injection consisted of between 250 and $500 \mathrm{nl}$ of a $2 \%$ solution of the dye in sterile distilled water (the smaller volumes being used in the younger animals) with the aim of producing an injection site with a dense central core of around $0.5-1.5 \mathrm{~mm}$ in diameter, involving all layers of the cortex without significantly invading the white matter (although some white matter involvement did occur occasionally; see Results).

In many of the kittens (Table 1) we made two adjacent injections (one of DY, the other of FB) into area 18, separated in the rostrocaudal plane by distances ranging from 1.0 to $2.5 \mathrm{~mm}$, thus producing an unstained gap of $0-1.45 \mathrm{~mm}$ between the closest boundaries of the dense cores of the two injection sites. The aim of this was not only to obtain an extensive series of data on divergence and convergence, but to use the incidence of double labeling to estimate the extent of arborization of individual association axons at different ages (as described in Ferrer et al., 1988).

In the normal animal, in which we injected one hemisphere with two pairs of DY and FB injections (N16, Table 1), the injected zones were separated by a distance of $8 \mathrm{~mm}$ rostrocaudally, with the more caudal pair centered just rostral to APO. Because of the topographic nature of the projection (see Ferrer et al., 1988) and because this was a mature animal in which convergence of projection was within the range of adult values (see Results), the two areas of labeling in area 17 were separated by several millimeters of unlabeled cortex. There was no ambiguity in relating each injection site to its resultant label.

In three MD animals we injected area 18 in both hemispheres, so as to compare the pattern of labeling in area 17 ipsilateral and contralateral to the deprived eye. We were very confident that the cells examined in area 18 did not include callosal neurons retrogradely labeled from the other hemisphere, despite the fact that MD leads to an expanded callosal pathway (Innocenti and Frost, 1979). For one thing, we placed the injections of dye (either DY alone in MD2 and MD3, or a DY-FB pair in MD1; Table 1) at different coronal levels on the two sides, staggered about $5 \mathrm{~mm}$ rostrocaudally with the most caudal injections around AP0, so that any interhemispheric cells labeled would have been out of register with the region of labeled association neurons. But in any case, we saw no large concentration of callosally labeled cells in any of the MD cats. This is presumably because the injections in area 18 were always placed some distance from the border with area 17 , avoiding the main termination zone of callosal axons. Labeled association cells in area 17 always lay well away from the area $17 / 18$ border, within the body of area 17 . Thus, our results could be interpreted unambiguously.

Histological preparation. Four or five days after injection of retrograde tracer (Table 1), each animal was rapidly and deeply anesthetized with a lethal dose of sodium pentobarbitone $(20 \mathrm{mg}$, i.p.) and perfused transcardially with a bolus of normal saline followed by a phosphate-buffered solution of $4 \%$ paraformaldehyde and then a phosphate-buffered solution of $10 \%$ sucrose. The whole brain was dissected from the skull, photographed, and placed in the $10 \%$ buffered sucrose solution to equilibrate fully for $1-2 \mathrm{~d}$.

From all cats except MD3, 50- $\mu \mathrm{m}$-thick coronal sections of the visual cortex and lateral geniculate nucleus (LGN) were cut on a freezing microtome. In MD3, $25 \mu \mathrm{m}$ sections were cut. A 1-in-3 series of sections from each animal was reserved unstained until it had been examined for fluorescently labeled cells, and was later counterstained with cresyl violet. A sccond 1-in-3 scrics of the cortex was stained for cytochrome oxidase activity (Wong-Riley, 1979), which helps reveal the borders of areas 17 and 18 even in kittens (Price, 1985).

Analysis. Sections were examined in a fluorescence microscope to reveal cells retrogradely labeled with FB, DY, or both. Camera lucida 
drawings were made of the locations of all labeled neurons. These drawings were used to construct two-dimensional surface views of the distributions of labeled cells in area 17, following the method described in Ferrer et al. (1988) and used subsequently by Price et al. (1992, 1994) and Ferrer et al. (1992). Briefly, in every section examined for fluorescence throughout the region of labeling, the positions of all labeled cells in the superficial layers of area 17 (upper layer 4 and above) were projected up to the cortical surface along the trajectory of the radial columns of cells visible after Nissl staining. The whole series of sections was aligned and combined to generate a two-dimensional view of the distribution of these association cells, collapsed on to the cortical surface.

In both normal and MD animals we measured the density of retrogradely labeled cells in area 17 along the mediolateral and rostrocaudal directions through the middle of the territory of labeling. In this analysis we relied exclusively on data derived from DY-injection sites, not only because FB seems to be a slightly less sensitive tracer (the maximum densities of cells labeled from FB injections were about 5-10\% lower than those from DY injections) but also because we did not have a complete set of data from FB injections (Table 1). To quantify the overall distribution of labeled cells, the entire unstained 1-in-3 series was examined in the fluorescence microscope and all the labeled cells were counted in a $100 \times 100 \mu \mathrm{m}$ square area positioned mediolaterally in the center of the labeled territory, with its lower border set midway through layer 4. These sampling areas were aligned in successive sections by careful superimposition of section boundaries and other features. Density was similarly measured along a lamina-parallel mediolateral tranche, in a coronal section from the middle of the labeled territory.

To derive a single representative value of labeled cell density, for comparison with results from other animals, we also took five sampling zones $(100 \times 100 \mu \mathrm{m} \times$ the thickness of the section, i.e., $50 \mu \mathrm{m}$ in all but MD3 where it was $25 \mu \mathrm{m}$ ) in the superficial layers in the center of the labeled region in area 17, where the density of labeled cells was highest, counted all labeled cells in each of these five zones, converted the values to density, and took the average as the peak density resulting from that injection. We also calculated the approximate relative volume of the superficial layers of area 17 at all ages, so that we could apply appropriate corrections. We examined coronal cytochrome oxidasestained sections, in which the borders of area 17 are fairly easily recognizable (Price, 1985), at four equally spaced rostrocaudal levels along the striate cortex. In each one we measured the mediolateral extent of area 17 along the middle of layer 4 , and the radial thickness of the upper half of the gray matter, from the middle of layer 4 (which is recognizable even in the youngest kittens) to the bottom of layer 1 , at four positions equally spaced mediolaterally across area 17 . The rostral limit of area 17 is very difficult to position accurately with histological techniques alone, but our previous electrophysiological studies suggest that its position relative to the rostral and caudal poles of the brain does not change significantly postnatally (Blakemore and Price, 1987). Thus, we simply measured the total rostrocaudal length of the cerebral hemispheres of all the brains used in this study and assumed that the rostrocaudal extent of area 17 is always roughly a constant proportion of the length of the entire hemisphere. For each normal and MD animal, we took the mean values for each of these dimensions and normalized them to the corresponding means in adult cats (assigned values of 1.0). We then calculated the relative volume of the superficial layers of area 17 at all ages by multiplying the three fractions.

We estimated the convergence of the area 17 to 18 projection quantitatively in normal and MD animals, using data from both DY and FB injections (because both tracers gave similar values). The anatomical convergence of a projection is simply the linear extent of the region of neurons in one area that project to a single point in the other, which can be estimated as the difference between the linear dimensions of a region of retrogradely labeled cells in one area and of the injection site in another (see Salin et al., 1989; Price et al., 1994). In visual areas, such as 17 and 18 , with quite precise retinotopic organization, it is useful to consider convergence in functional terms, by relating it to differences in the scale of representation of visual space in the two areas (see Ferrer et al., 1988). Fortunately, in the more rostral part of the visual cortex, where we were investigating, the magnification factor, $M$ (in millimeters cortex per degree of visual field), along the rostrocaudal direction is roughly the same in areas 17 and 18 at each coronal level (Tusa et al., 1978, 1979). Therefore, any tendency for the rostrocaudal extent of the territory of cell labeling in area 17 to exceed the rostrocaudal diameter of the injection site in area 18 would suggest that the projection from area 17 provides each zone in area 18 with input from a larger fraction of the retinotopic map. Indeed, using identical techniques, we have previously shown that the territory of labeled clusters in area 17 of normal adult cats is, on average, $1.6 \mathrm{~mm}$ longer in an anteroposterior direction than the injection site (in the rostral part of the visual cortex). This leads to functional convergence such that each zone in area 18 typically receives input from a region in area 17 representing a portion of the visual field $1.6 \mathrm{M}^{-1}$ degrees more extensive in elevation (since the vertical dimension of the field is represented along the rostrocaudal axis of the cortex), where $M$ is the rostrocaudal magnification factor (Ferrer et al., 1988).

We determined the position of each injection site not only by examining it in the sections stained with cresyl violet (Price and Zumbroich, 1989) and for cytochrome oxidase (which reveals the boundaries of areas 17,18, and 19, even in kittens; Price, 1985), but also indirectly by observing the relative sizes and distribution of cells labeled in the LGN (as described in Price and Blakemore, 1985a,b).

Throughout this article, including all graphical analysis, animals are referred to by the age at which area 18 was injected, even though there was a 4-5 d survival period before perfusion (Table 1 ). This is because we were principally interested in the cells of origin of the association projection lying in the supragranular layers of area 17, whose pattern appears to mature in normal cats by selective elimination of axons from area 18, without the death of the cells of origin (Price and Blakemore, $1985 \mathrm{~b}$ ); thus, those neurons that were retrogradely labeled had axons in the region of the injection site at the time of injection, but some may have lost them by the time of perfusion.

\section{Results}

\section{Injection sites}

In young kittens, exuberant corticocortical and interhemispheric connections sprcad widely throughout the whitc matter but many do not penetrate the overlying gray matter (Innocenti and Clarke, 1984; Clarke and Innocenti, 1986; Price and Zumbroich, 1989; reviewed by Price, 1991). Thus, injections of retrograde tracer in immature animals would be expected to label a more widespread population of neurons if they involve the underlying white matter. We were very conscious of this potential problem, particularly since at least some tracers may diffuse more freely in the immature nervous system. In fact, we noted no evidence for this with DY and FB; both tracers produced injection sites with well-defined, dense cores at all ages (Fig. 1). There was as little diffuse spread of tracer in the youngest kittens as in mature animals (in this respect, DY and FB are more satisfactory tracers than horseradish peroxidase, although the main results with all three are similar; see Price and Blakemore, 1985a). For every injection we took careful note of whether the dense core of the injection site (probably corresponding to the uptake zone; Bullier et al., 1984a; Ferrer et al., 1988) invaded the white matter. In all but two animals (N1 and N2) our protocol for injection was successful in giving sites that were entirely restricted to the gray matter. Figure 1 shows examples of injection sites confined to the gray matter (Fig. $1 a, b$ ) and one that slightly involved white matter (Fig. 1c). In N1 and N2 (2-d-old kittens) both the DY and the FB injections just entered the white matter. These cases are identified throughout the Results. The injections shown in Figure 1 were all in young kittens; in older animals, it was less problematic to achieve injections restricted to gray matter (mainly because the cortex thickens considerably after birth), and all injections appeared similar to those illustrated in our previous publications (e.g., Ferrer et al., 1988).

\section{Developmental changes in the distribution of association cells in area 17 projecting to area 18}

Figure 2 shows typical examples of the patterns of retrograde labeling of cells in area 17 after injections of DY into area 18 in normal and MD animals of various ages. In the youngest 

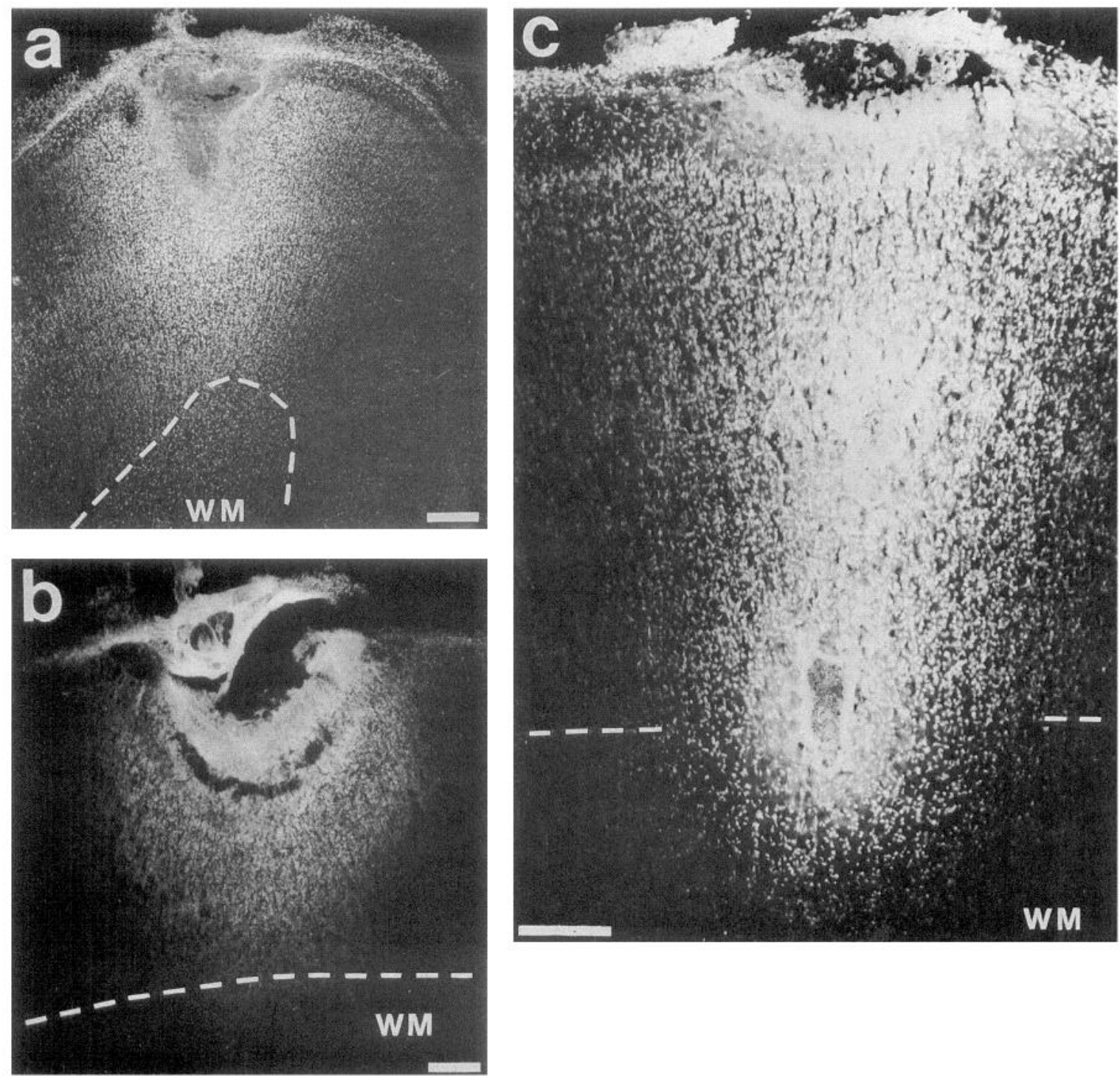

WM

Figure 1. Fluorescence photomicrographs of coronal sections through the centers of injection sites in area 18 in young kittens: $a$, DY in a 3-dold (N4); $b$, FB in a 9-d-old (N6); $c$, DY in a 2-d-old (N2). In each photomicrograph the border between layer 6 and the white matter ( $W M$ ) is indicated by a broken line. In most animals described in this article the dense core of the injection site did not stray into the white matter (as in $a$ and $b$ ); any labeling seen below layer 6 in these cases was intracellular, probably within subplate cells, which are known to project into the overlying cortex in young kittens (Friauf et al., 1990). In a few of the youngest animals the core of the injection did enter the white matter by a few hundred micrometers (as in $c$ ). Where such contamination occurred it is documented in Results. Scale bars, $200 \mu \mathrm{m}$.

normal kittens (2-9 d), labeled cells are distributed as two continuous, extensive, parallel bands, of high cell density, along the superficial and the deep layers of area 17 , with relatively few labeled cells in between, in lower layer 4 (Fig. $2 a$ ). In somewhat older normal kittens (13-30 d; Fig. 2b,c), selective elimination of some of the early area 17 to 18 connections has resulted in the appearance of clusters of labeled association cells. At $30 \mathrm{~d}$, the boundaries of these immature clusters are not yet sharply defined and they extend right up to the deep border of layer 1, where migrating immature neurons are still arriving (Shatz and Luskin, 1986). The clusters appear relatively large, compared with their mature form, and this difference in size becomes all the more significant if one takes into account the fact that the cortex is still growing at this stage. Between about $19 \mathrm{~d}$ of age and adulthood the cortex of area 17 roughly doubles in volume (see Fig. $5 b$ and text below), yet the clusters decrease in absolute size (compare Fig. $2 b, d$ ). This implies that the actual restriction of association cells within each cluster during this period is even more exaggerated than it appears.

Labeled cells remain numerous in the deep layers up to 3-4 weeks of age and they clearly undergo a similar process of restriction, to form clusters aligned with those in the superficial layers (Fig. 2b,c), before the density of labeled cells in the deep layers decreases dramatically to produce the adult pattern (Fig. $2 d$ ). In the oldest normal kittens and adult cats the clumps of association cells have become more discrete, most assuming a characteristic triangular appearance with the densest, more widespread groups of labeled cells lying relatively deep in the supragranular layers (Fig. $2 d$ ); few labeled cells are now present in the infragranular laminae.

These results confirm our previous observation that the clusters of association cells in area 17 appear during the second and 


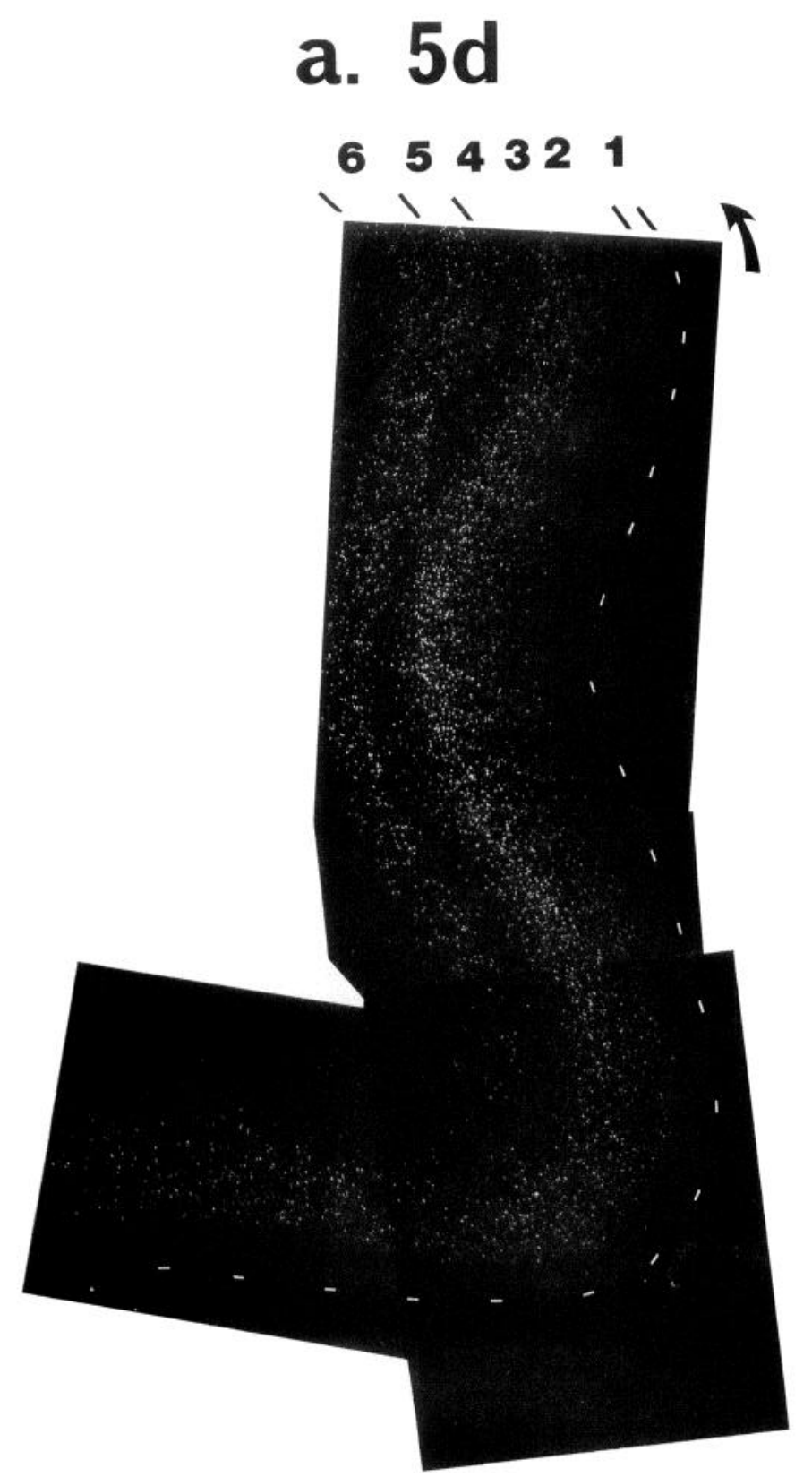

\section{b. 19d}

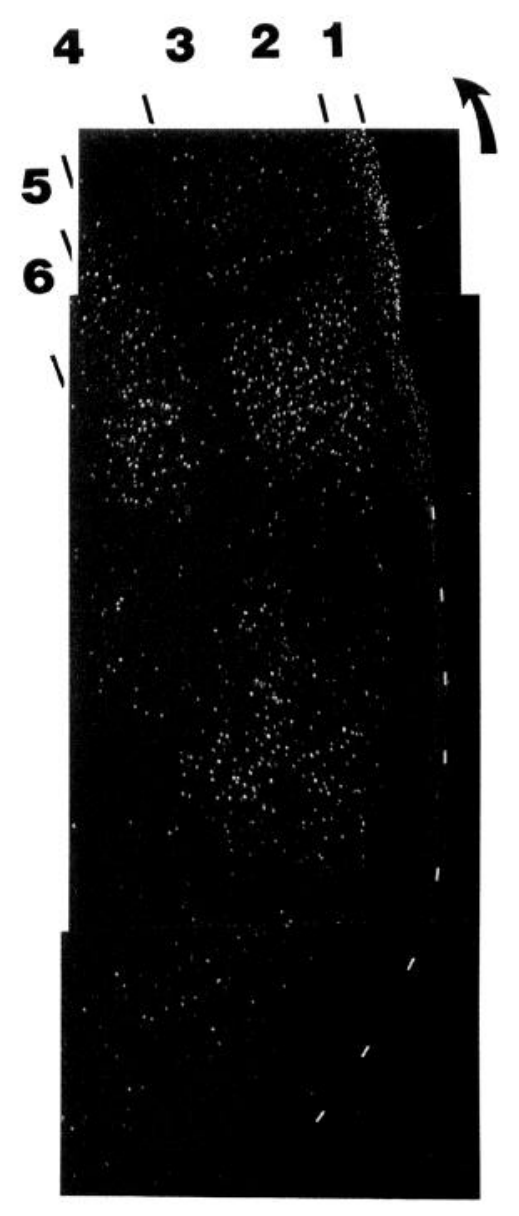

Figure 2. Montages of fluorescence photomicrographs of DY-labeled cells in coronal sections through area 17 after injection of the tracer in area 18 in the left hemisphere of a normal 5-d-old kitten (N5;a), the left hemisphere of a normal $19 \mathrm{~d}$ kitten (N9; $b$ ), the left hemisphere of a normal $30 \mathrm{~d}$ kitten $(\mathrm{N} 12 ; c)$, the right hemisphere of a normal adult cat $(\mathrm{N} 18 ; d)$, the left $(L)$ and right $(R)$ hemispheres of a $82 \mathrm{~d} \mathrm{MD} \mathrm{kitten} \mathrm{(MD1;} \mathrm{left}$ eye deprived; $e$ ), and the left hemisphere in an adult MD cat (MD6; left eye deprived; $f$ ). The arrows by each montage indicate the direction of the area 17/18 border, dorsal and lateral to the region of labeling. The broken lines mark the pial surface of each section. Cortical laminae are indicated, as defined in adjacent cresyl violet- and cytochrome oxidase-stained sections; layers 2 and 3 are still forming in the youngest kittens and the upper border of layer 4 cannot be precisely defined (Shatz and Luskin, 1986). The scale bar above $d$ refers to all photographs.

third postnatal weeks (Price and Blakemore, 1985a), but demonstrate that the full refinement of the clusters takes longer. They also suggest that the disappearance of projections from the deep layers continues for several weeks longer than we previously thought.

As is seen in Figure 2, $e$ and $f$, monocular deprivation did not prevent the emergence of clustering of association cells. Nevertheless, there were consistent differences between the distributions of labeled cells in normal and MD animals, some of which we have quantified. The clusters seem larger and not as well defined in MD animals, and the density of labeled cells is consistently higher than in normal cats of similar age (Fig. 2; compare $d$ with $e, f$; this is quantified below). The number of association cells remaining in the deep layers is also generally greater in MD animals.

We obtained a more complete impression of the results from two-dimensional surface views of the labeled cells. Clustering of corticocortical neurons across the whole of the labeled zone is apparent in all the examples from normal and MD animals in Figures 3 and 4 . However, as suggested from single coronal sections (Fig. 2), the overall density of labeled cells and the size of the clusters appear greater in the MD cats than in the normals. 


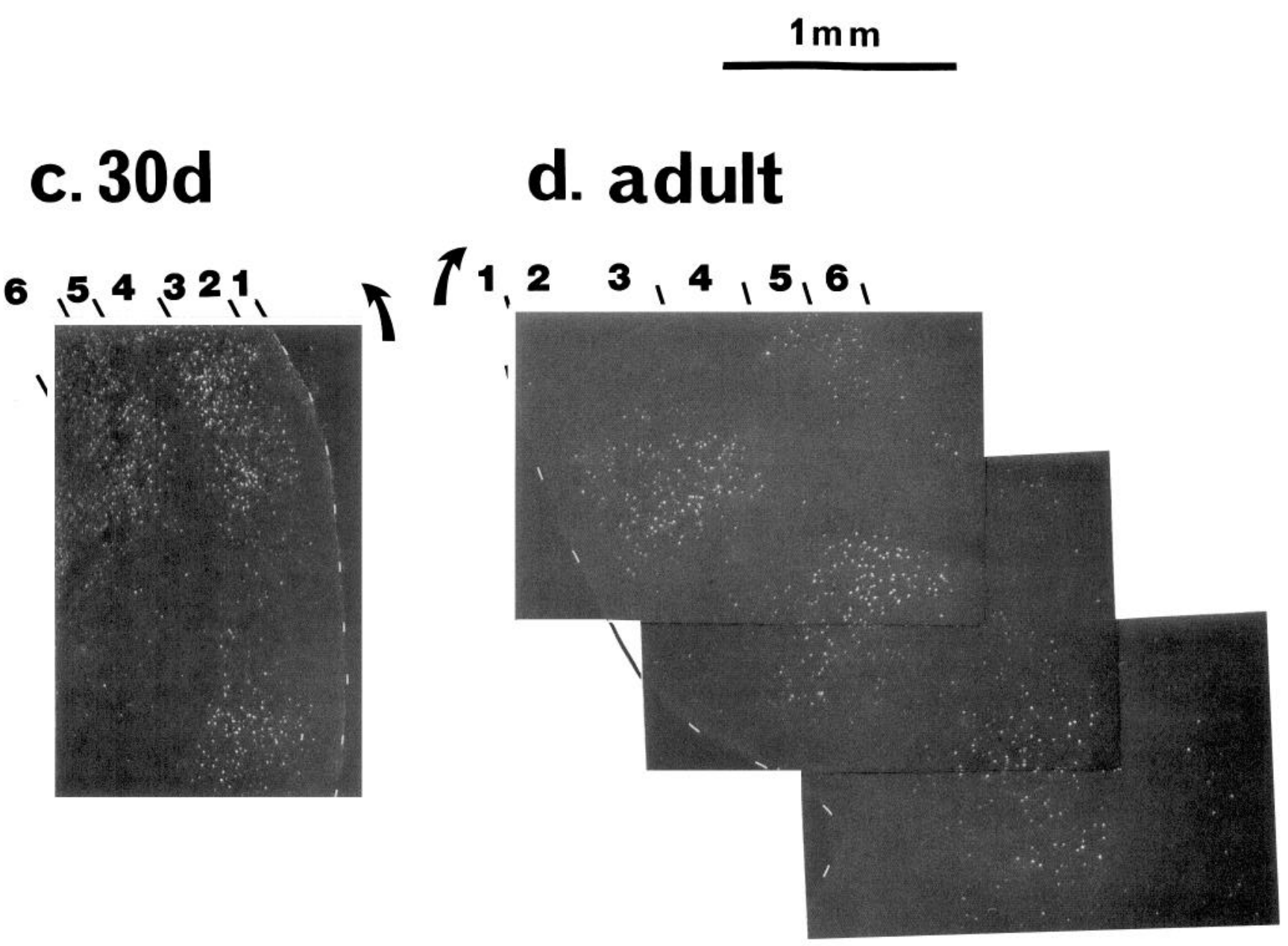

Figure 2. Continued.

Although comparison of Figure $3, b$ and $c$, suggests that there may be a difference between the pattern of association clusters ipsilateral and contralateral to the MD eye, this was not a consistent observation. This example shows a somewhat denser population of labeled cells ipsilateral to the deprived eye, but the other MD animals had heavier labeling on the contralateral side (see Fig. $5 c$ ). Such differences were almost certainly due to technical variations, such as the exact size, position, or density of the injection site. Such differences between the results of injections in the same or similar animals were small compared with the clear tendency for the density of labeled cells and the size of the clusters to be greater in MD animals than in agematched normals. Figure 4 , showing results for a normal adult (Fig. 4a) and an adult MD cat (Fig. 4b), illustrates all these differences vividly. We decided to quantify these differences for all animals.

\section{Density of retrogradely labeled cells}

In every case there was a general decrease in the proportion of labeled cells from the middle of the whole labeled region to its periphery (analyzed further below), presumably because many association cells near the edge of the region send axons that diverge beyond the injection site and are therefore unlabeled. In animals older than about $20 \mathrm{~d}$, where clusters have emerged the density of labeled cells obviously declines from the center to the edge of each individual cluster. We derived a single es- timate of the highest density (peak density; see Materials and Methods) of labeled cells from each injection, as this reflects more accurately the true density of area 17 to 18 cells.

In Figure $5 a$, the peak density of association cells in the superficial layers is plotted against age. There was a rapid decrease in peak density during the first postnatal month or so, followed, in normal animals, by a more gradual decline over at least several further months. From about 3 months on, the densities of labeled cells in the MD animals were consistently higher than in normal cats. The cell densities from the very young animals, $\mathrm{N} 1$ and N2, in which white matter was involved in the injection (Fig. 1c), are included (as open squares) in Figure 5 because they were not obviously different from those for other kittens of similar age in which the white matter was not contaminated.

Now, both the thickness and the surface area of the cortex increase early postnatally. The resulting increase in volume is disproportionately large for the superficial layers, which thicken considerably as migrating neurons continue to arrive, enlarge, and separate (Shatz and Luskin, 1986). Clearly, any change in the volume of the cortex with age would affect the density of labeled neurons even if there were no underlying change in the proportion of cells projecting to area 18 . It is even conceivable that the late difference between normal and MD animals could be due to a retardation of cortical growth in MD cats. Therefore, we corrected the data in Figure $5 a$ for the enlargement of the cortex during development (see Materials and Methods). 


\section{e. 82d MD}

L

ipsilateral

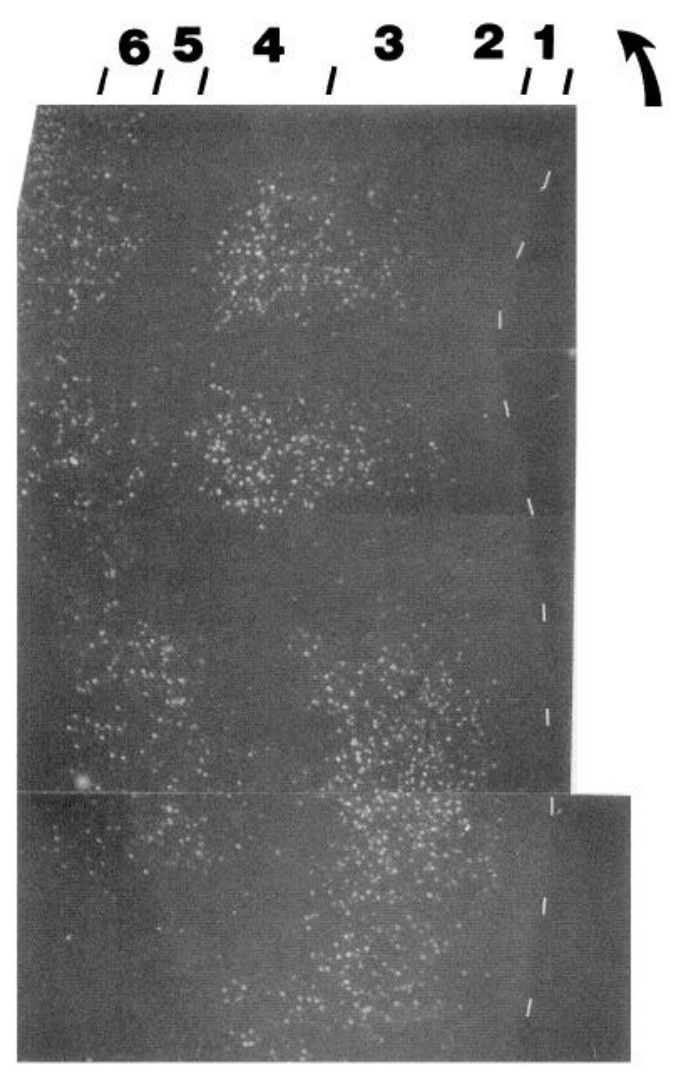

Figure 2. Continued.

The change in the correction factor with age is shown in Figure $5 b$. The upper layers of the striate cortex increase fourfold in volume postnatally, most of this growth occurring during the first month. There was no consistent difference in volume between matched normal and MD animals and, therefore, a single function was fitted to all the data points.

The result of applying this correction function to the data in Figure $5 a$ is shown in Figure $5 c$. Each peak density has been multiplied by the corresponding value of the correction function from Figure $5 b$. The rapid decrease in peak density during the first postnatal month in Figure $5 a$ is now seen to be more than accounted for by expansion of the gray matter. Far from there being a decline in the absolute number of association cells from immediately after birth, there is probably a net increase in the number of corticocortical neurons projecting from area 17 to area 18 during the first month, presumably through the formation of new axonal connections. However, beyond that age there is a prolonged decrease in corrected density in normal cats, implying that the number of corticocortical cells projecting from each cluster in area 17 genuinely declines between 1 and about 6 months of age. In MD cats there is no such late decrease in corrected density: the number of projection neurons seems to remain steady at a higher value, corresponding to that seen in normal animals at about 1 month, when the number of projecting cells is at its peak.

\section{The fraction of area 17 occupied by labeled cells in normal and $M D$ cats}

To quantify the fraction of area 17 covered by association cell clusters, we examined the main, central region of the labeled area seen in each two-dimensional reconstruction. Peripheral clumps that appeared relatively smaller and sparsely labeled were excluded because they were presumably incompletely labeled. We drew a line linking the centers of the outermost clusters of this remaining central region to define a region of analysis (see Price et al., 1994). Using an image analysis system, we measured the surface area of cortex within this region covered by labeled clusters and that devoid of labeled cells. 


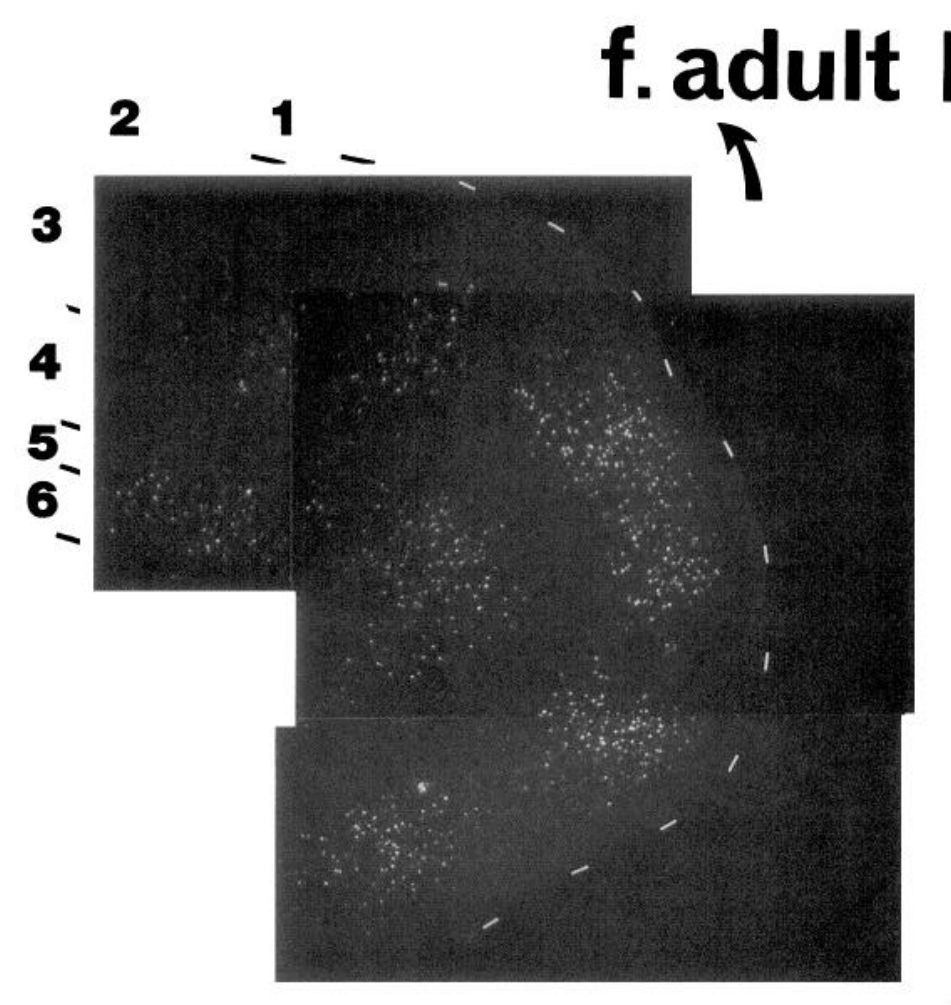

Figure 2. Continued.

Data were derived from three pairs of normal and MD cats of similar ages. The first pair comprised a normal animal aged $105 \mathrm{~d}$ and an MD cat aged $101 \mathrm{~d}$ (N16 and MD2), the second pair a normal animal aged $143 \mathrm{~d}$ and an MD animal aged 166 $\mathrm{d}$ (N17 and MD4), and the third a normal and MD adult (N18 and MD6).

The percentage of the surface area of the cortex that contained labeled cells was similar in the three normal cats: $77.1 \%$ in N16, $82.9 \%$ in $\mathrm{N} 17$, and $79.9 \%$ in N18. In all three MD animals the percentage occupied by labeled cells was higher, $90.1 \%$ in MD2, $90.3 \%$ in MD4, and $89.3 \%$ in MD6. The values from MD animals are between $7.4 \%$ and $13.0 \%$ higher than in normals. These data confirm our initial impression that monocular deprivation results in larger clusters of association cells projecting to area 18 . We compared the average center-to-center distance of the clusters of labeled cells in these three age-matched pairs, and found no difference in one pair and only a tiny difference in the other two pairs (cluster centers slightly closer in the MD cats). Thus, the increase in the surface area occupied by clusters in MD animals is primarily due to the individual clusters being larger.

\section{Developmental changes in convergence and divergence of the projection from area 17 to area 18}

Even casual observation of single sections suggested that the degree of convergence and divergence of this projection changes enormously over the first postnatal month. In very young kittens, single tiny injections of area 18 labeled neurons over a substantial fraction of the total rostrocaudal length of area 17 and over its entire mediolateral extent, whereas in older animals, both normal and MD, the labeling was always restricted to a small territory of clusters, typically about $3 \times 5 \mathrm{~mm}$ in total surface area (see Figs. 3, 4).
Figure 6 plots rostrocaudal anatomical convergence against age for all normal and MD kittens and cats in which we obtained a complete set of sections through the labeled area. All data are for the projection from the superficial cortical layers of area 17; interestingly, the projection from the deep layers in young kittens was always narrower (as can be seen in Fig. 2a), either because the convergence of this projection was never as high as that from the superficial layers or because it narrowed prenatally. The data point for normal adult cats $(1.6 \mathrm{~mm})$ is the mean value for the nine animals studied by Ferrer et al. (1988). Anatomical convergence decreases substantially, by more than a factor of 4 , the most rapid phase occurring during the first postnatal month. There is no difference between normal and MD cats in this respect. Values from injections that strayed into the white matter in very young kittens are indicated in Figure 6 by open squares; they are all greater than those in which white matter was not involved, a result that is compatible with evidence that area 17 initially sends axons extensively in the white matter, many of them ramifying under non-topographically corresponding parts of other visual areas but not entering the gray matter (Price and Zumbroich, 1989).

Measurement of convergence in the mediolateral dimension is complicated by two factors. First, in kittens younger than about 3 weeks, single injections in area 18 produced labeling across the entire mediolateral extent of 17 . Also, the interpretation of anatomical convergence is influenced by the fact that the magnification factor is larger in area 17 than in 18 along the mediolateral dimension by a factor of about 1.68 for the rostral visual cortex in adults (see Ferrer et al., 1988; Price et al., 1994), and there is no reason to believe that this ratio would vary substantially during the period of cortical expansion. This leads one to expect that if the extent of functional convergence is similar in all directions (as in the adult; Ferrer et al., 1988), the 


\section{a. NORMAL}

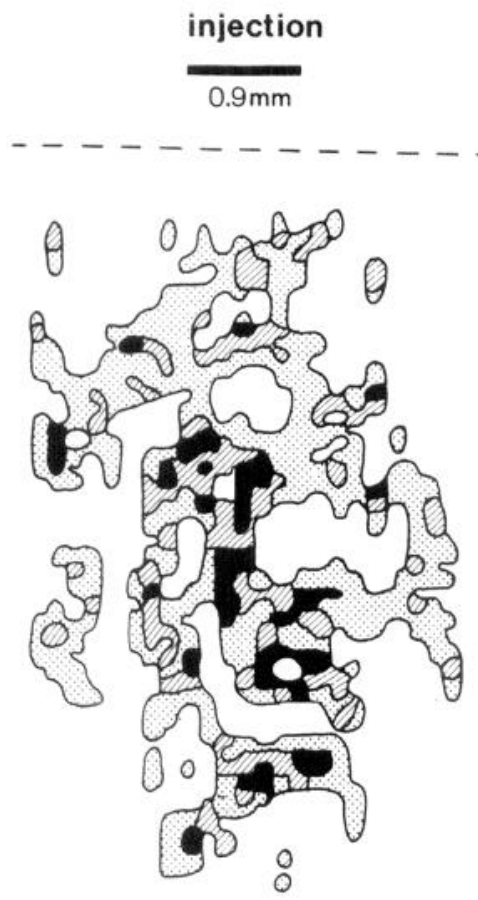

b. IPSILATERAL

to deprived eye

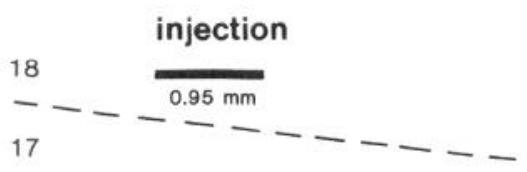

c. CONTRALATERAL to deprived eye

injection

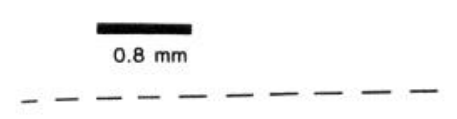

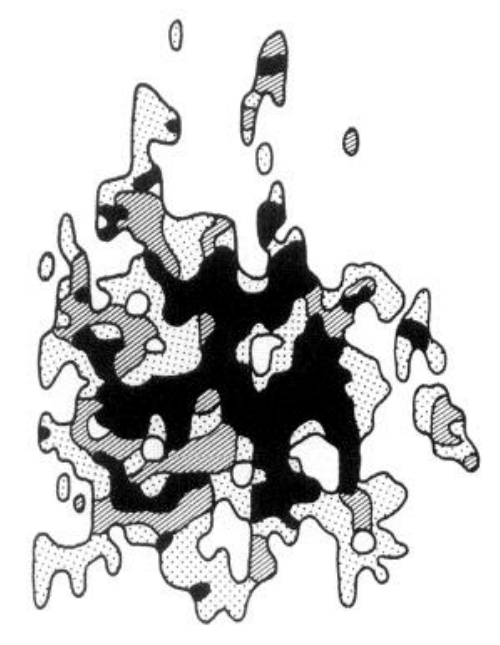

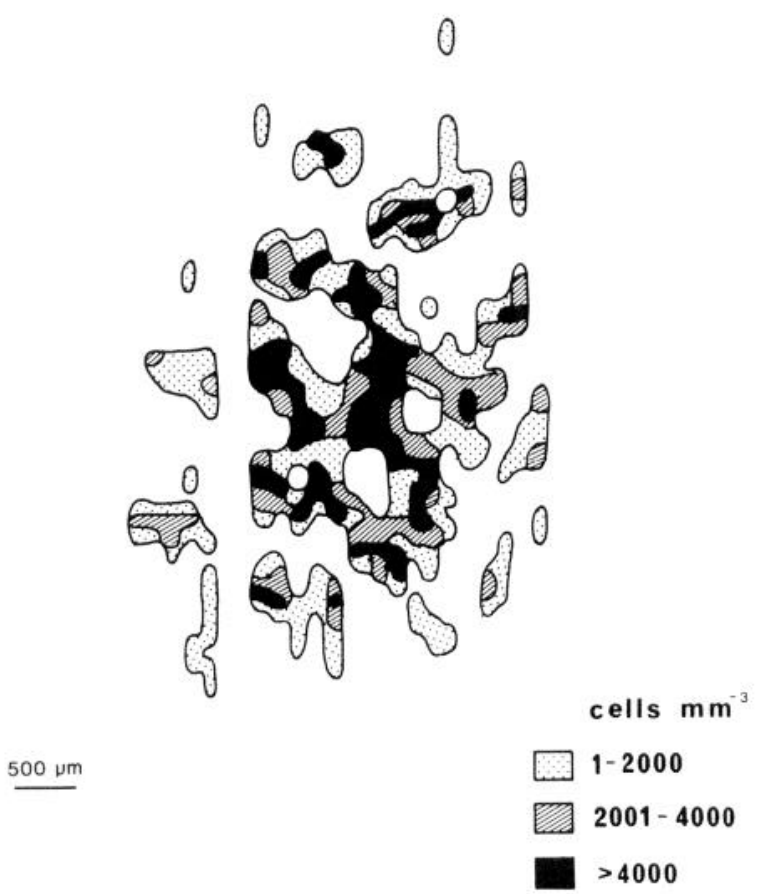

Figure 3. Two-dimensional surface views of area 17 (reconstructed from a 1 -in-3 series of 50 - $\mu$ m-thick coronal sections) in the right hemisphere of a normal cat (N16) aged $105 \mathrm{~d}(a)$ and an MD cat (MD2) aged $101 \mathrm{~d}$, ipsilateral $(b)$ and contralateral $(c)$ to the deprived eye (left eye). The various forms of shading (see key) indicate the densities of labeled cells in the upper layers of the area 17 (layers 2, 3 and upper 4) following single injections of DY into area 18. The method for making these reconstructions has been described in detail elsewhere (Ferrer et al., 1988); briefly, the positions of all labeled cells in coronal sections of area 17 are drawn with a camera lucida and then projected radially on a plane equivalent to the cortical surface, where their numbers within bins measuring $0.10 \mathrm{~mm}$ (mediolateral) $\times 0.05 \mathrm{~mm}$ (rostrocaudal) are counted to give densities. Thus, the clusters of labeled cells are collapsed into two dimensions at the cortical surface. In each diagram, the area 17/18 border is marked by a broken line; the rostrocaudal position and width of the dense core of the injection site in area 18 are indicated schematically by the thick bar at the top of each reconstruction (the length of the bar is to scale but its distance from the area $17 / 18$ border is not).

anatomical convergence should be larger by this factor in the mediolateral than in the rostrocaudal dimension at all ages. From $19 \mathrm{~d}$ onward (once the label did not fill the entire mediolateral width of area 17) this was indeed the case: the territory of labeled clusters was nearly always elongated mediolaterally by about the expected amount.

During this period of shrinking convergence, the cortex expands greatly (see above). Assuming that areas 17 and 18 always occupy the same fraction of the entire cortex, our measurements of the total length of the hemispheres at different ages provide us with an indication of rostrocaudal expansion of both areas. Between birth and the end of the first postnatal month, the rostrocaudal length of the brain increases by about $55 \%$ to reach adult values. A projection that always links fixed points would be expected to increase in measured anatomical convergence in proportion to this increase in rostrocaudal length. Thus, the true decrease in the convergence of the area 17 to 18 projection with age must be even greater than that shown in Figure 6.

\section{Distribution of labeled cell density across area 17}

We wondered whether the excessive convergence and divergence of the area 17 to 18 pathway in young kittens is due to the presence of a relatively small number of aberrantly projecting axons, or to the entire population of connections being uniformly highly divergent. In each animal we measured the distribution of density of labeled cells along rostrocaudal and mediolateral directions through the center of the labeled area, using the sampling procedure described in Materials and Methods. Typical results are shown in Figure 7 ( $a, b$ for an adult; $c, d$ for a 3-d-old kitten). The distributions for the adult, which extend about $2.7 \mathrm{~mm}$ rostrocaudally and $3.4 \mathrm{~mm}$ mediolaterally (for an injection site $1.1 \mathrm{~mm}$ wide rostrocaudally and $0.8 \mathrm{~mm}$ mediolaterally), have clear peaks, corresponding to the individual clusters through which the sampling lines ran. The distributions for the kitten are typical of those for animals aged $9 \mathrm{~d}$ or less, which are roughly bell shaped, often with a slight skew, variable in direction and magnitude. Small periodic fluctuations 


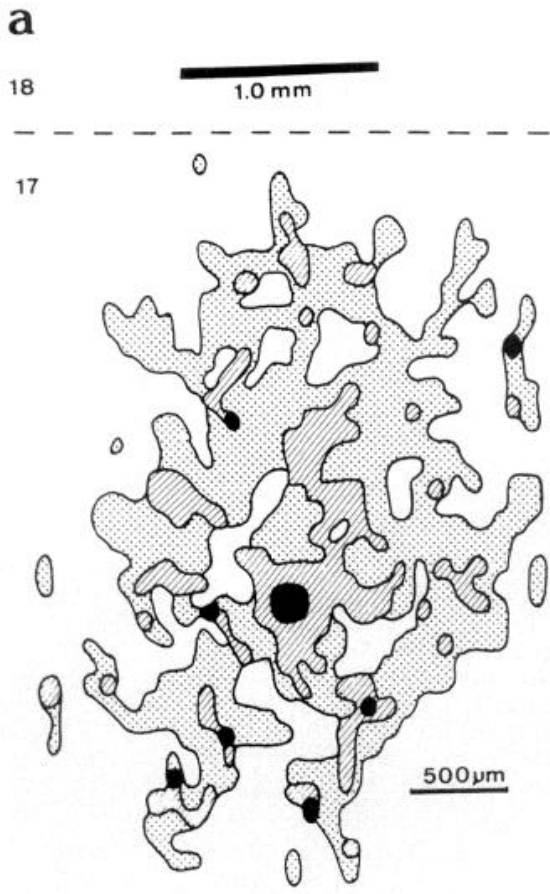

b
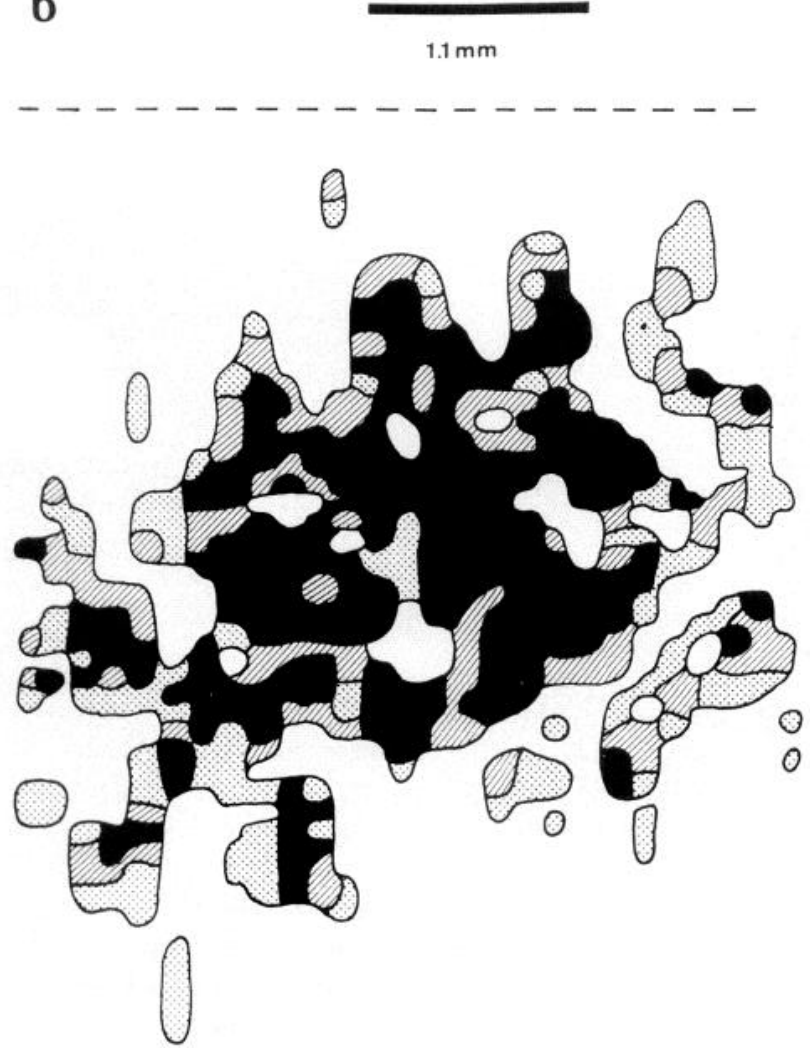

Figure 4. Two-dimensional surface views of area 17 showing densities of labeled cells in the superficial layers in the right hemisphere of a normal adult cat $(\mathrm{N} 18 ; a)$ and a MD adult cat (MD6: left eye closed; b) after single injections of DY into area 18 . Conventions are the same as in Figure 3. in density, indicated by arrows in Figure 7, $c$ and $d$, may represent emerging clusters of association cells.

Note that the distribution of labeled cells actually fills the entire mediolateral width of area 17 in the kitten (Fig. 7d), despite the fact that the injection site was less than $1 \mathrm{~mm}$ across in that direction. This, together the anisotropy of mediolateral magnification already mentioned, obviously complicates quantitative interpretation, and we therefore restricted further analysis to the rostrocaudal direction.

Consider the simple model illustrated in Figure $8 a$. The data of Figure $7 c$ suggest that, in young kittens, each diminishingly small region of area 17 projects very divergently to innervate a much larger zone in area 18 , which we shall term the innervation territory (whose surface area is represented by the large solid circle). The uptake region of the injection site in area 18 (shown as a smaller, stippled circle), typically about $1 \mathrm{~mm}$ in diameter, is considerably smaller than the innervation territory. If each cell in area 17 projects with a highly localized arbor (as the evidence below suggests they do), and the axons from each small domain of area 17 are distributed with uniform density across the total innervation territory, then the density of labeled cells in any small region of area 17 would be expected to be proportional to the amount of overlap between the innervation territory (large circle) and the uptake site (small circle). That area of overlap is equal to

$$
(a-r) \sqrt{2 a r-a^{2}}+r^{2} \arcsin (a / r-1)+\pi r^{2} / 2,
$$

where $r$ is the radius of the uptake site and $a$ is the amount by which its diameter overlaps the innervation territory.

Assuming that the innervation territory for axons from every small domain in area 17 is similar in extent, it is possible to use Equation 1 to calculate the expected distribution along area 17 of cells labeled by a single injection in area 18 . The actual rostrocaudal width of the injection uptake site (shown as a horizontal bar in Fig. $7 c$ ) was taken as $2 r$, and the diameter of the innervation territory was set at $2 r$ less than the rostrocaudal extent of the distribution of labeled cells along area 17 from Figure $7 c$, this obviously produces a predicted distribution whose borders coincide with the observed edges of the actual distribution. The resulting function from Equation 1, multiplied by a constant to normalize it to the observed maximum density of labeled cells in Figure $7 c\left(27 \times 10^{3}\right.$ cells $\left.\cdot \mathrm{mm}^{-3}\right)$, is plotted in Figure $8 a$. The assumption of a uniform distribution of axon arbors from each small region of area 17 obviously produces a flat-topped function, which is a poor fit to the peaked distribution of labeled neurons actually observed.

Clearly, a better fit would be obtained by assuming that the density of axons is highest in the center and decreases toward the periphery of the innervation zone. We therefore implemented Equation 1 in a computer graphics program for various nonuniform distributions of axon terminals, integrating under the region of overlap to calculate the expected distributions of labeled neurons. Neither a skewed normal distribution nor a linear decrease of axon terminal density provided an optimal fit to the experimental data. The best fit was obtained with a terminal distribution that decreased linearly from its peak out to a diameter of about $4.5 \mathrm{~mm}$, surrounded by a uniform, low density of terminals ( $5 \%$ of the peak value) extending to the edge of the innervation territory. This model, illustrated schematically in Figure $8 b$, generated the function plotted below, normalized to the observed peak density.

We conclude that, in young kittens, the axon arbors from each 

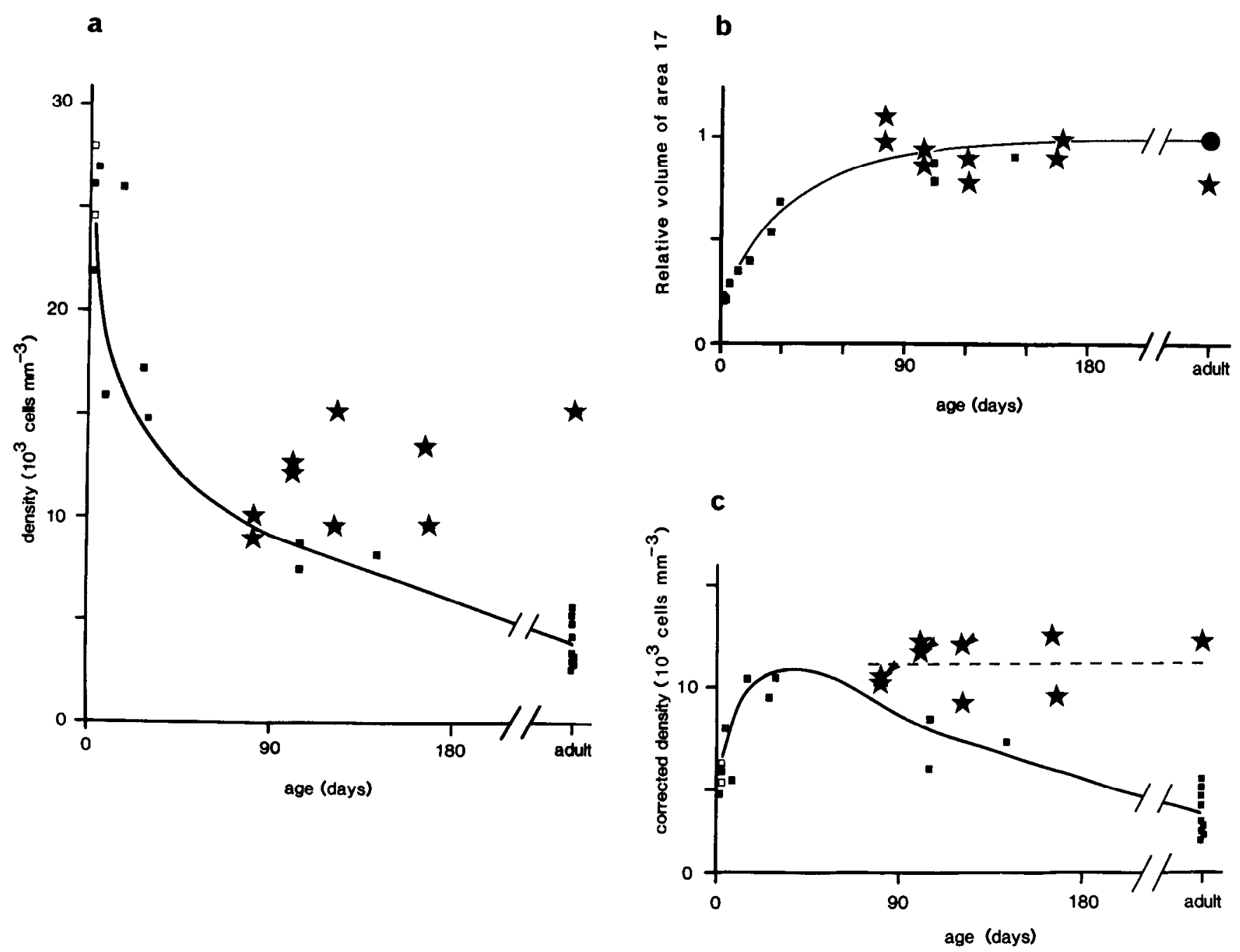

Figure 5. $a$, The average peak density of DY-labeled cells in area 17 is plotted against age for normal animals (squares) and MD animals (stars). Open squares plot data derived from kittens in which the injection slightly involved the white matter. The smooth curve was fitted by eye to the data from normal animals. $b$, Change in the relative volume of area 17 with age in normal cats (squares) and MD animals (stars); the average value from normal adults is designated 1.0 (indicated by the solid circle). The smooth function was fitted by eye to all the data points. $c$, Data in $a$ have been multiplied by the function in $b$ to correct for expansion of the cortex. Any variation with age on this ordinate thus represents an actual change in the absolute numbers of association cells projecting to area 18 in the regions of highest cell density. The smooth curve was fitted by eye to the data from normal cats; the broken line was fitted to data from MD cats. In three MD cats, we injected both ipsilateral and contralateral to the deprived eye (MD1-MD3), and the data indicated with arrowheads are from the contralateral hemisphere.

small region of area 17 are not distributed homogeneously across the innervation territory in area 18 , but project with higher, peaked density over a smaller central region. Thus, the underlying topography of the projection is more precise at early ages than the overall convergence and divergence suggests. The major change in convergence with age is due to the elimination of sparse remote axonal projections.

\section{Arborization of individual axons: evidence from double labeling}

In adult cats, injection of two different dyes close together in area 18 (within the range of divergence of axons from area 17) results in overlap of the territories of cells retrogradely labeled by the two dyes in area 17. However, even within clusters labeled by both dyes, the proportion of individual neurons that are double labeled is very low, up to only $4.4 \%$ (Ferrer et al., 1988). This indicates that most association fibers from area 17 arborize over a region of area 18 very much smaller than the total di- vergence of all axons from a single association cluster. This result fits well with Gilbert and Wiesel's (1989) evidence that this projection connects individual columns of matched orientation preference, even though it arises from clusters that are considerably larger than such individual columns.

In view of the huge convergence and divergence of the projection in young kittens (see above), we were interested to see whether individual axons also arborize much more extensively at early ages. In five normal kittens, aged $2 \mathrm{~d}, 9 \mathrm{~d}, 27 \mathrm{~d}, 30 \mathrm{~d}$, and $105 \mathrm{~d}$, we made pairs of injections, each pair consisting of a DY and an FB injection separated by a short distance anteroposteriorly. In none of these cases was the white matter involved in the injections. We obtained a complete 1 -in-3 series of drawings of single- and double-labeled cells through the region of overlap of DY and FB labcling in area 17 resulting from each pair of injections.

In all of these animals we could identify double-labeled cells with appearances similar to those shown in Ferrer et al. (1988) 
Figure 6. Changes with age in convergence of the projection from area 17 to area 18 , measured along the rostrocaudal axis, in normal cats (squares) and MD cats (ringed circles). Open squares plot data derived from kittens in which the injection of tracer slightly involved white matter. Convergence is defined as the amount by which the total rostrocaudal extent of zone of labeled cell clusters in area 17 exceeds the rostrocaudal width of the dense core of the injection site in area 18 (see Materials and Methods). The value plotted for normal adults is the mean convergence $( \pm \mathrm{SD})$ for the nine cases described previously by Ferrer et al. (1988).

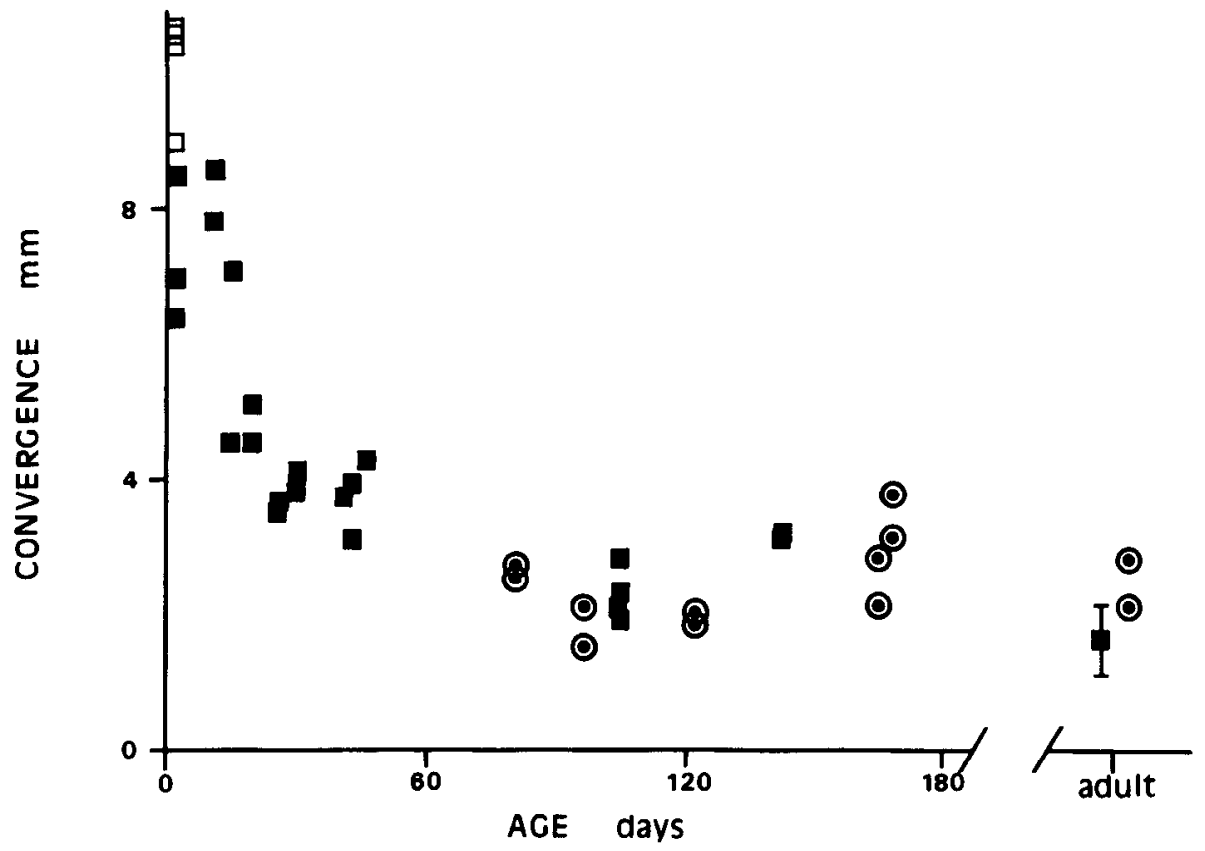

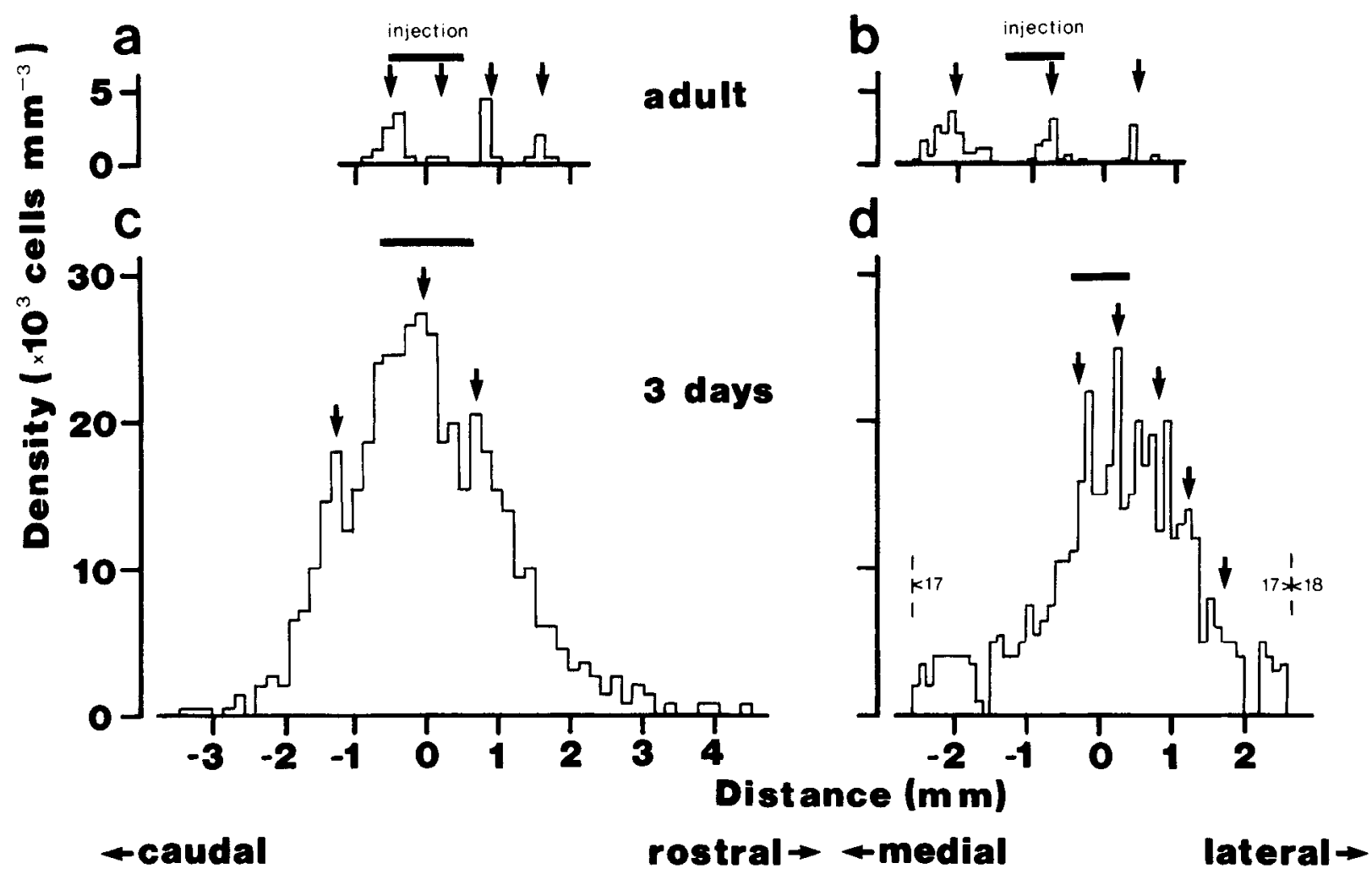

Figure 7. The density of labeled cells was measured along the rostrocaudal $(a, b)$ and mediolateral $(c, d)$ directions, through the centers of the labeled region in area 17, using the sampling method described in Materials and Methods. $a$. Histogram plotting the density of labeled cells along the rostrocaudal axis in an adult cat. Density was measured in $100 \mu \mathrm{m}$ squares, aligned through each of the 1 -in-3 series of $50 \mu \mathrm{m}$ sections, and thus each bin represents $150 \mu \mathrm{m}$ of distance along the parasagittal axis. The rostrocaudal position and diameter of the dense core of the injection site in area 18 are indicated by the solid bar; zero on the abscissa is set at the middle of the injection site. The territory of labeled cells extends farther both rostrally (by about $1.3 \mathrm{~mm}$ ) and caudally (by about $0.4 \mathrm{~mm}$ ) in this example. The obvious clustering of labeled cells is reflected in the multiple peaks in the histogram (arrows). $b$, The density of labeled cells along the mediolateral direction, from the same adult cat. Density was again measured in a $100 \mu \mathrm{m}$ square whose lower edge was shifted along the middle of layer 4 in the coronal section at the middle of the labeled area. The solid bar represents the mediolateral width of the injection site. $c$, Histogram, similar to that in $a$, for kitten N4 (3 d of age; Table 1 ). The distribution is bell shaped, with its peak at the coronal level corresponding to the middle of the injection site, but it is skewed slightly. Periodic small fluctuations in density, indicated by arrows, may represent emerging clusters of association cells. $d$, Histogram, as in $b$, for kitten N4. The borders of area 17 are indicated by broken lines: labeled cells are found throughout the entire mediolateral extent of area 17. 

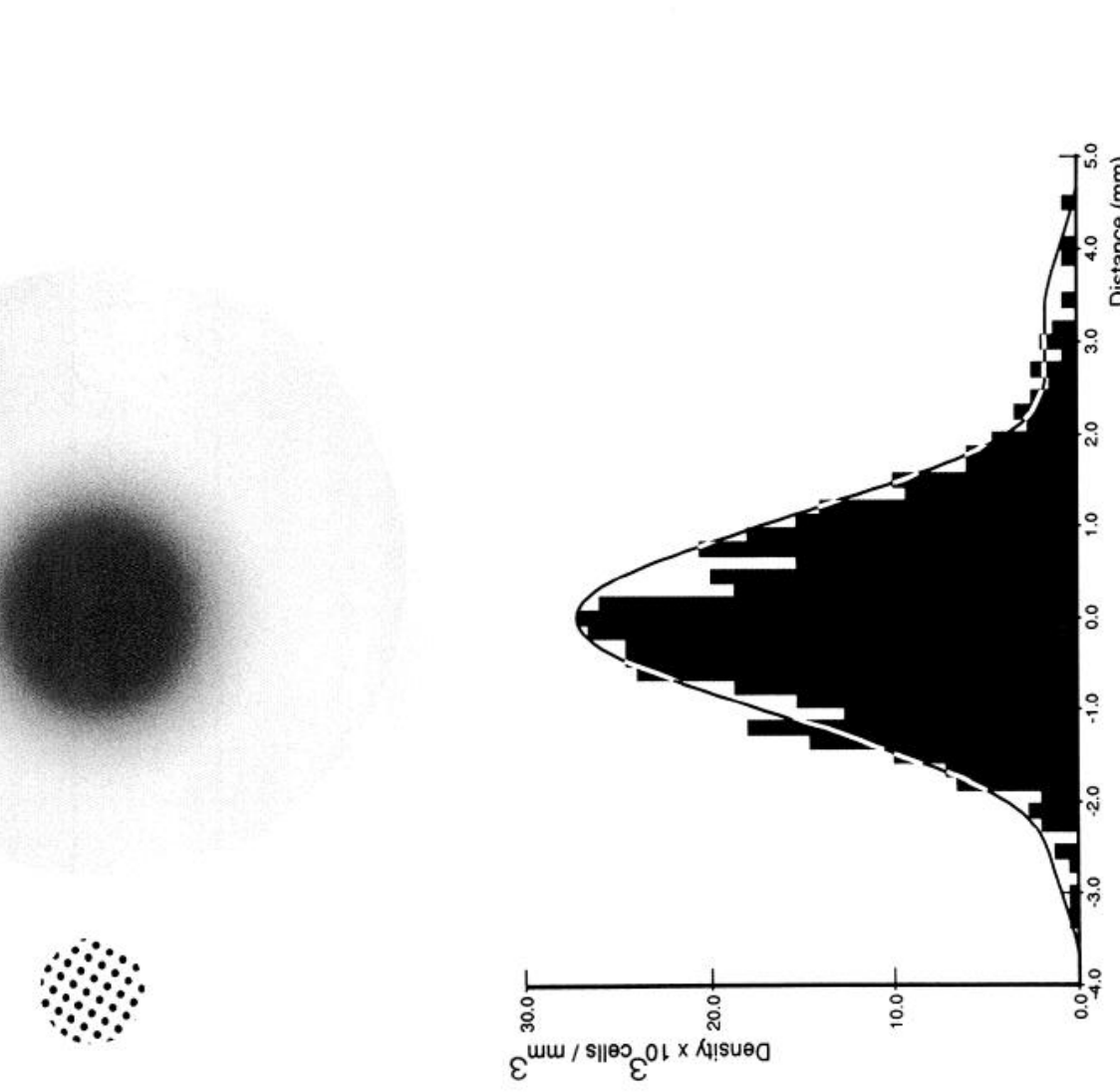

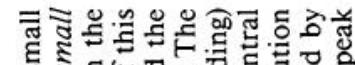

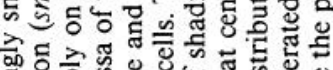

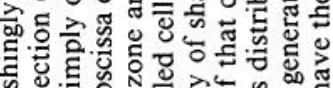

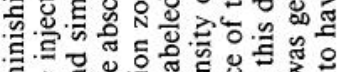

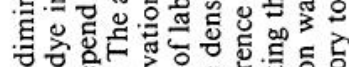
5 象记

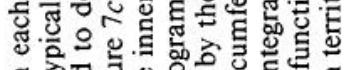
छ

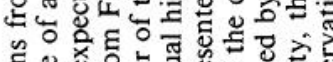

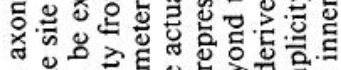

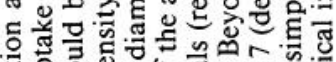

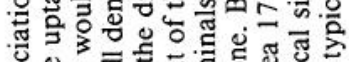

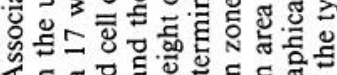
<声西

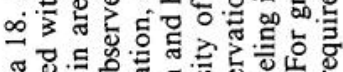

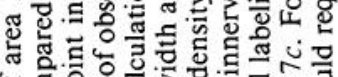
등응

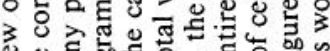

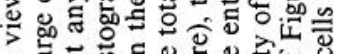
의 $\pi$.

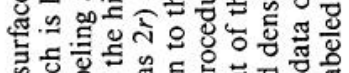

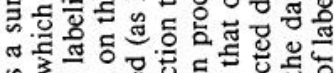

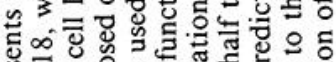

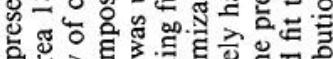

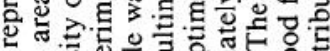
․ㅢ 멸

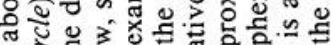

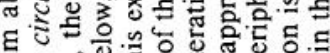

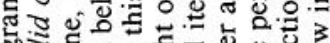

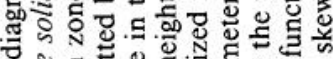

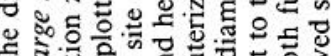

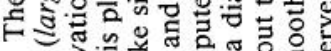
纪改

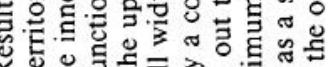
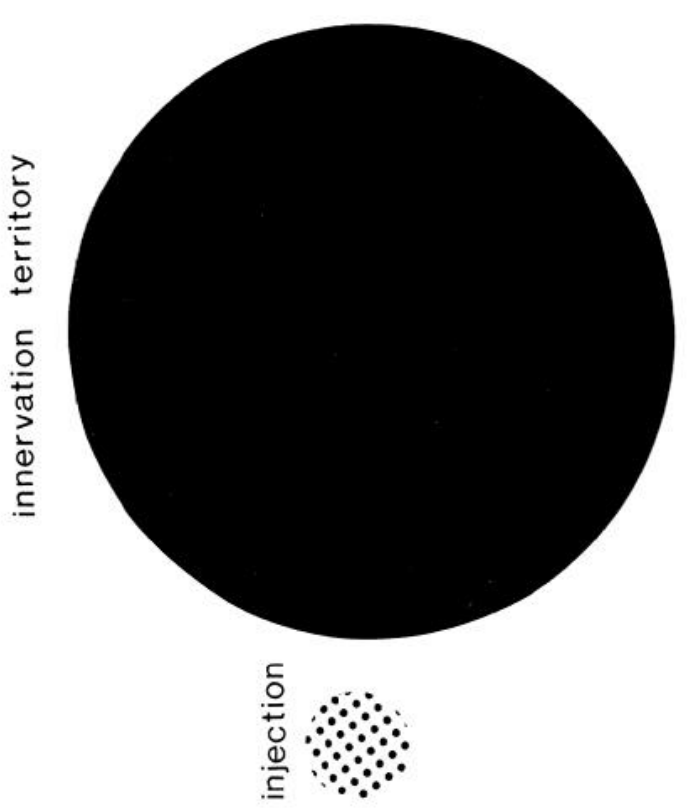

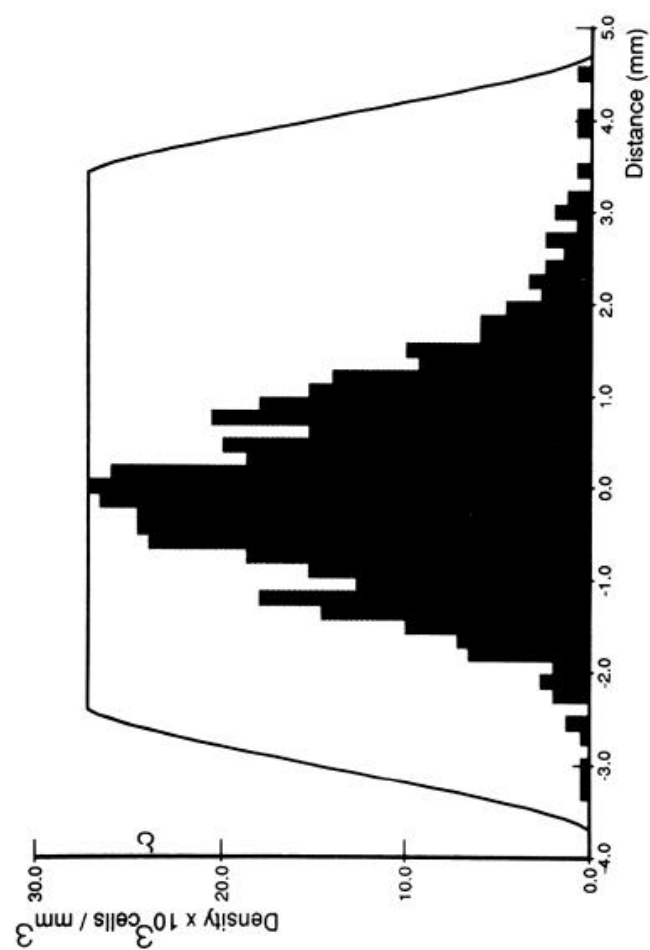

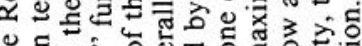

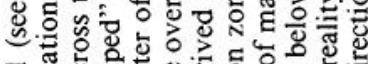

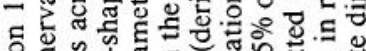

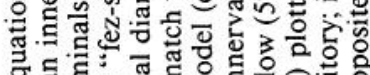
岀 ส

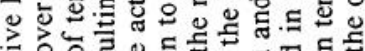

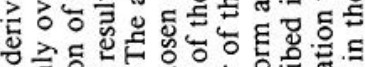

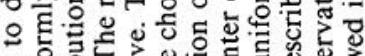

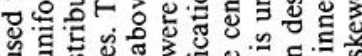

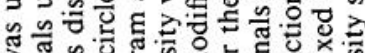

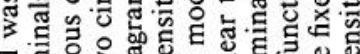
ฮ छี

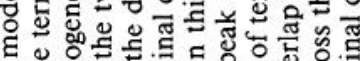

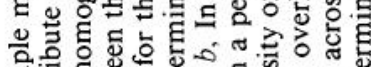

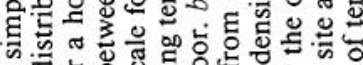

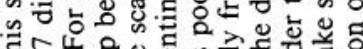

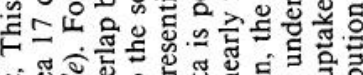

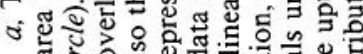

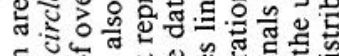
$\infty . \Xi 0$

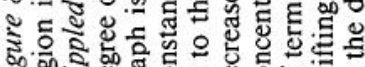
분 
Figure 9. Camera lucida drawings of sections through area 17 of a normal 2-d-old kitten (N3) in which area 18 was injected with FB and DY. $a$ and $b$, The injection sites in area 18 are shown (solid areas): they were separated rostrocaudally by $0.25 \mathrm{~mm}$ of unstained cortex. In $b$, dots indicate labeled cells (DY and FB intermingled); the region of densest label is outlined by the box and is enlarged in $c . c$, Double-labeled cells are marked as stars; open circles represent FB-labeled cells; solid circles are DY-labeled cells. This was the youngest animal in which we made pairs of injections and the smallest separation between them, but nevertheless, there were very few double-labeled cells even in regions with high densities and roughly equal proportions of DY- and FB-labeled cells. Scale bar, $0.1 \mathrm{~mm}$.

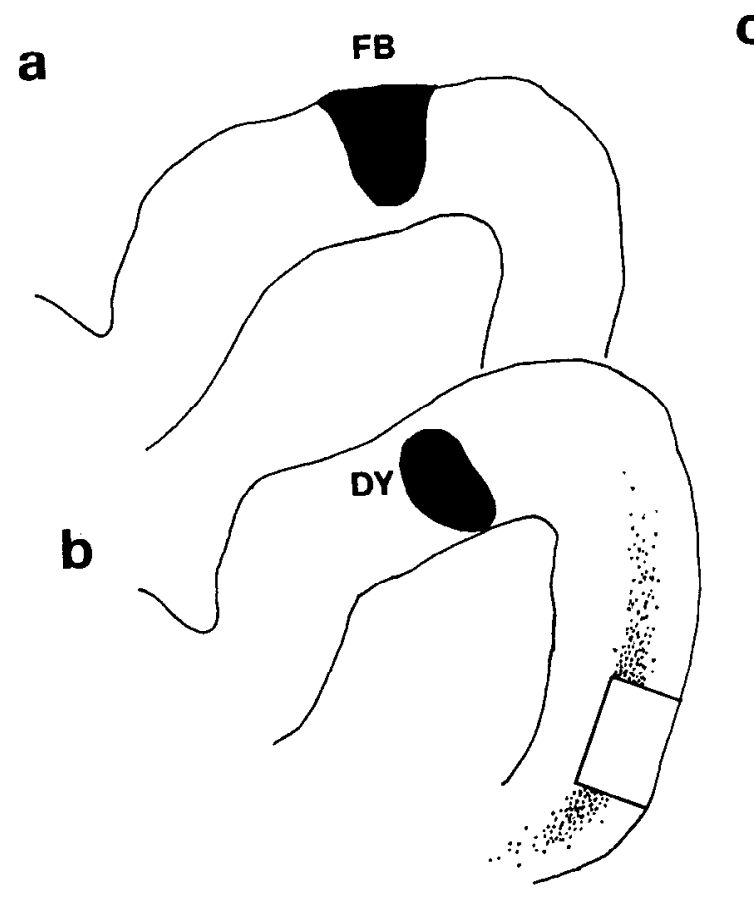

C

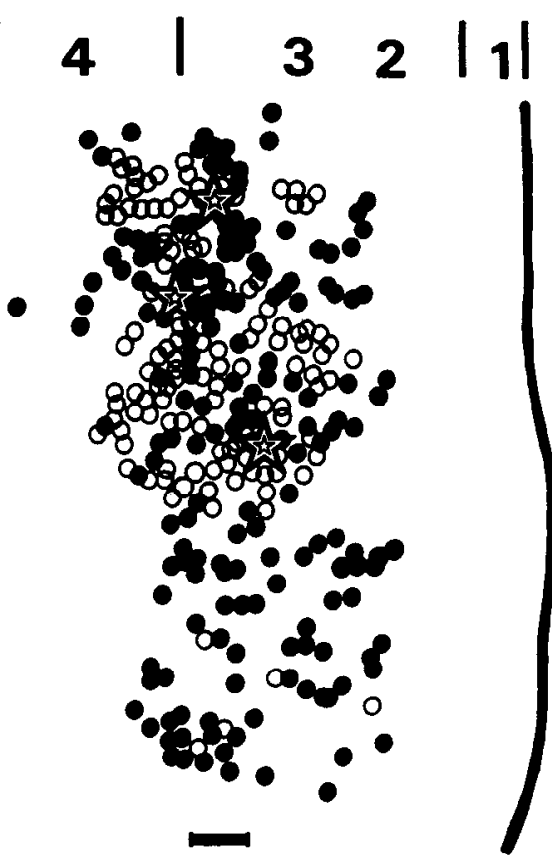

and Price and Ferrer (1993). However, in none was the incidence of double labeling within the clusters containing both dyes very high. In the older kittens (26-105 d), the adjacent injections were always separated by between 0.55 and $0.70 \mathrm{~mm}$ of unstained cortex. The percentage of cells in the overlap region that were double labeled was between only $2.0 \%$ (at $27 \mathrm{~d}$; separation of injections, $0.55 \mathrm{~mm}$ ) and $6.7 \%$ (at $30 \mathrm{~d}$; separation of injections, $0.7 \mathrm{~mm}$ ). In the $2 \mathrm{~d}$ and $9 \mathrm{~d}$ animals the injections were separated by $0.25 \mathrm{~mm}$ of unstained cortex, slightly less than in the older kittens, but the percentages of labeled cells were still only $8.7 \%$ and $7.6 \%$, respectively. Figure 9 illustrates a section through the zone of overlap between FB- and DY-labeled cells in the $2 \mathrm{~d}$ kitten; even in sections such as this, where there was a very high density of label, we observed very few double-labeled cells. We have previously shown that, after double injection of FB and DY at a single point in area 18, almost all cells in area 17 become double labeled (Ferrer et al., 1988). We conclude that, just as in adult cats, widespread arborization of arca 17 to 18 association connections seems relatively uncommon in young kittens. Even in the first postnatal week, fewer than $10 \%$ of association axons appear to arborize over a rostrocaudal extent of more than $0.25 \mathrm{~mm}$ within area 18 .

\section{Discussion}

\section{Normal development}

The pathway from area 17 to area 18 is richly developed at birth but contains both exuberant and aberrant components: the cells of origin in area 17 are distributed as two uniformly dense bands, one superficial, the other in the deep layers, with massive convergence and divergence of their projection to area 18. Within the first 2 postnatal weeks the continuous distributions of association cells start to transform into clusters, aligned in the deep and the superficial layers. Over the following weeks the clusters become smaller, their boundaries sharpen, the deeplayer cells largely disappear and the convergence of the projection decreases enormously.

In regions of the superficial layers projecting to area 18 our analysis of association cell density corrected for cortical growth suggests that the overall number of projection cells first increases to a peak about 1 month after birth and then gradually declines over several months to adult levels. Thus, although the clusters in the upper layers are well established by a month of age (Price and Blakemore, 1985a,b), further refinement of the projection continues for much longer. Recent studies of the development of area 17 have demonstrated a similarly prolonged period for complete maturation of intrinsic connections (Luhmann et al., 1986; Callaway and Katz, 1990).

The increase in the total number of cells projecting to area 18 from the superficial layers of area 17 , occurring simultaneously with a decrease in the deep-layer projection, is unlikely to be due to migration of neurons, with axons already in area 18 , from deep to superficial layers. Cell migration certainly continues after birth in the cat (Shatz and Luskin, 1986), but if migration were the explanation, we ought to have seen significant numbers of labeled neurons in transit through deep layer 4 at some point, which we never have, in this or previous work (Price and Blakemore, 1985a,b). It seems more likely that the reduction in the deep-layer projection is at least partly due to cell death (Price and Blakemore, 1985b).

Studies with anterograde tracers indicate that area 17 sends out axons prenatally to form an extensive plexus in the white matter, and that some of these axons have started to penetrate the gray matter of area 18 at around the time of birth (Price and Zumbroich, 1989). The increase of peak density of association cells in the upper layers during the first month after birth probably represents the tail end of this process of ingrowth of corticocortical fibers. However, this early strengthening of the projection from the corresponding part of area 17 is already accompanied by a loss of connections. There is evidence that the sculpting to form projection clusters, which occurs over the first postnatal month, is causcd by the selective withdrawal of axons from area 18 without death of their cell bodies in area 17 (Price and Blakemore, 1985b). Our present results suggest that axon withdrawal continues for many months after birth, 
resulting in not only the elimination of exuberant input to the peripheral parts of the vast innervation territory but also the twofold reduction in association cell density in the centers of the clusters themselves, between 1 month and adulthood (see Fig. $5 c$ ). It seems possible that these prolonged changes in the density of projection (which outlast the classical sensitive period for the effects of monocular deprivation) could be due to a process of uniform and partial axon withdrawal from the whole initial exuberant termination field. Indeed, quantitative modeling (see Fig. $8 b$ ) suggests that, within the initial enormous territory in area 18 innervated by any small region in area 17 , there is a central, topographically appropriate concentration of axon arbors, covering a much smaller territory, only about twice the size found in the adult. It is possible that the uniform, sparse, widespread distribution of axons around this central concentration corresponds to exuberant fibers from area 17 that penetrate only the lowest part of the cortical plate in inappropriate regions of area 18, but are later lost (Price and 'Zumbroich, 1989). It would be interesting to see whether injections deliberately restricted to the superficial layers of area 18 in young animals label a more adult-like distribution of cells in area 17.

The association projection that finally emerges is remarkably efficiently organized. Not only do the cells in area 17 appear to innervate columns of similar orientation preference in area 18 (Gilbert and Wiesel, 1989), but they lie in clusters that are aligned with regions of binocular input and are sufficiently large and closely spaced to provide a full representation of the visual field (Price et al., 1994). Moreover, the convergence is such that the cells in area 18, with their larger receptive fields, receive from a group of cells in area 17 whose smaller receptive fields cover at least the same region of the visual field (Ferrer et al., 1988; Price et al., 1994). The sculpting of the projection from its initially exuberant form might be achieved through some kind of functional validation, perhaps depending on Hebbian synapses detecting correlations in visually driven activity resulting in the strengthening of connections carrying correlated signals (Stent, 1973). In fact, Price and Blakemore (1985a) have shown that the basic clustering of association cells still occurs in binocularly deprived kittens and is therefore not crucially dependent on visual stimulation. However, there remains the possibility that the refinement of convergence and of the exact distribution of clusters is affected in visually deprived animals, as it seems to be for intrinsic horizontal connections in area 17 (Luhmann et al., 1986, 1990).

Despite the enormous divergence and convergence of the projection as a whole, and the presence of axons from many cells that are destined to lose their connection to area 18 , the small numbers of association neurons double labeled by closely spaced injection of different dyes into area 18 of young kittens imply that the arbors of most of the axons entering area 18 are very small right from the start-perhaps no more than the $100 \mu \mathrm{m}$ in extent estimated for adults (Ferrer et al., 1988). Perhaps this tightness of individual projection is important in the process of selective elimination: any axon whose narrow arborization does not fall in the correct region may fail to be validated and hence stabilized.

\section{Effects of monocular deprivation on development of the} pathway

In the preceding article (Price et al., 1994) we showed that the clusters of association neurons in area 17 of normal adult cats tend to lie above the distinct patches of afferent terminals in layer 4 carrying input from the ipsilateral eye. Since these regions also receive input from the contralateral eye, they represent zones of high binocularity, and cells recorded within the clusters were less often monocularly dominated than those outside (Price et al. 1994). In view of this relationship to the ocular dominance architecture, we thought that monocular deprivation, which leads to restriction of territory occupied by input from the deprived eye, might alter the maturation of the association cell clusters. We imagined that, if the formation of association clusters is matched to the ipsilateral eye patches, the clusters would be much smaller in the hemisphere ipsilateral to the deprived eye in MD cats. In fact, there was no hint of this. The clusters of association cells in MD cats still tended to be centered over the shrunken ipsilateral eye patches, but they were larger than normal, on both sides of the brain (Figs. 2-4), the density of association cells within the clusters was higher than normal (Fig. 5 ), and there was excessive persistence of projection neurons in the deep layers of area 17 (Fig. 2). Thus, it appears that in MD cats, many cells that would normally lose their projection to area 18 do not do so. Interestingly, refinement of the overall convergence of the association projection proceeds quite normally (Fig. 6), which contrasts with the callosal pathway, where monocular deprivation results in the preservation of an expanded contralateral projection (Innocenti and Frost, 1979).

This result demonstrates that the dimensions of the association clusters are not determined by the size of ipsilateral eye patches nor is the number of association cells proportional to the amount of input from the ipsilateral eye. What could explain the fact that association clusters seem tied to regions of ipsilateral input, yet are increased in size and cell density when one eye, even the ipsilateral eye, is deprived? A clue may be provided by our previous observation that binocular deprivation also does not prevent clustering but seems to result in a reduction in the density of projecting cells (Price and Blakemore, 1985a). We cannot make a direct comparison between the two studies because those on binocularly deprived animals used HRP as the retrograde label, and the fluorescent dyes employed here visibly label more neurons. However, for each group of deprived animals, we can compare results with matched normals. In the older MD animals of the present study the uncorrected peak density of association cells in the superficial layers was 200 $400 \%$ of that in normal cats (Fig. $5 a$ ), whereas in binocularly deprived 28 -d-old cats it was only about $25-50 \%$ of that of normals of similar age (Table 2 of Price and Blakemore, 1985a). One possible explanation for this curious result is that the numbers of cells that keep their axons in area 18 is influenced by the overall level of activity in the visual cortex. This will, of course, be abnormally low in binocularly deprived animals and it might be this general inactivity that leads to the exaggerated loss of the association projection.

In the cortex of normal cats, where many cells are highly sensitive to the retinal disparity of stimuli (e.g., Barlow et al. 1967; Pettigrew et al., 1968), any three-dimensional visual scene will lead to the inhibition of a large proportion of neurons because of the presence of stimuli of inappropriate retinal disparity or unmatched orientations (Sengpiel et al., 1992) on the receptive fields in the two eyes. Obviously, such occlusion of responses cannot occur in MD animals. So, once the rapid shift in ocular dominance toward the nondeprived eye has taken place, the general level of evoked activity could actually be higher in MD animals than in normals. This hyperactivity might 
be responsible for the retention of association projections that would normally be lost.

Thus, the appearance of periodicity in the distribution of association clusters, like that of the ocular dominance architecture with which they are correlated, may not require patterned visual stimulation. But there are strong hints that the local refinement of the projection, which continues for such a long period after birth and which leads to rather precise functional matching between projecting and receiving cells, is influenced by visual activity.

\section{References}

Albus K, Meyer G (1981) Spiny stellates as cells of origin of association fibres from area 17 to area 18 in the cat's neocortex. Brain Res 210: 335-341.

Barlow HB, Blakemore C, Pettigrew JD (1967) The neural mechanism of binocular depth discrimination. J Physiol (Lond) 193:327-342.

Blakemore C, Price DJ (1987) The organization and post-natal development of area 18 of the cat's visual cortex. J Physiol (Lond) 384: 263-292.

Blakemore C, Van Sluyters R (1975) Innate and environmental factors in the development of the kitten's visual cortex. J Physiol (Lond) 248: 663-716.

Bullier J, Kennedy H, Salinger W (1984a) Bifurcation of subcortical afferents to visual area 17,18 and 19 in the cat cortex. J Comp Neurol 228:309-328.

Bullier J, Kennedy H, Salinger W (1984b) Branching and laminar origin of projections between visual cortical areas in the cat. J Comp Neurol 228:329-341.

Callaway EM, Katz LC (1990) Emergence and refinement of clustered horizontal connections in cat striate cortex. J Neurosci 10:1134-1153.

Clarke S, Innocenti GM (1986) Organization of immature intrahemispheric connections. J Comp Neurol 251:1-22.

Eldridge JL (1979) Bi-axial stereotaxic head holder. J Physiol (Lond) 295:2P-3P

Ferrer JMR, Price DJ, Blakemore C (1988) The organization of corticocortical projections from area 17 to area 18 of the cat's visual cortex. Proc R Soc Lond [Biol] 233:77-98.

Ferrer JMR, Kato N, Price DJ (1992) The organization of association projections from area 17 to areas 18 and 19 and to suprasylvian areas in the cat's visual cortex. J Comp Neurol 316:261-278.

Friauf E, McConnell SK, Shatz CJ (1990) Functional synaptic circuits in the subplate during fetal and early postnatal development of cat visual cortex. J Neurosci 10:2601-2613.

Gilbert CD, Kelly JP (1975) The projections of cells in different layers of the cat's visual cortex. J Comp Neurol 163:81-106.

Gilbert CD, Wiesel TN (1989) Columnar specificity of intrinsic horizontal and corticocortical connections in cat visual cortex. J Neurosci 9:2432-2442.

Innocenti GM, Clarke S (1984) The organization of immature callosal connections. J Comp Neurol 230:287-309.

Innocenti GM, Frost DO (1979) Effects of visual experience on the maturation of the efferent system to the corpus callosum. Nature 280: 231-234.
Luhmann HJ, Martinez-Millan L, Singer W (1986) Development of horizontal intrinsic connections in cat striate cortex. Exp Brain Res 63:443-448.

Luhmann HJ, Singer W, Martinez-Millan L (1990) Horizontal interactions in cat striate cortex: I. Anatomical substrate and postnatal development. Eur J Neurosci 2:344-357.

Pettigrew JD, Nikara T, Bishop PO (1968) Binocular interaction on single units in cat striate cortex: simultaneous stimulation by single moving slit with receptive fields in correspondence. Exp Brain Res 6:391-410.

Price DJ (1985) Patterns of cytochrome oxidase activity in areas 17, 18 and 19 of the visual cortex of cats and kittens. Exp Brain Res 58: 125-133.

Price DJ (1991) The development of visual cortical afferents. In: Vision and visual dysfunction, $\mathrm{Vol} 11$, Development and plasticity of the visual system, Chap 17 (Cronly-Dillon J, ed). New York: Macmillan Press.

Price DJ, Blakemore C (1985a) The postnatal development of the association projection from visual cortical area 17 to area 18 in the cat. J Neurosci 5:2443-2452.

Price DJ, Blakemore C (1985b) Regressive events in the postnatal development of association projections in the visual cortex. Nature 316:721-724.

Price DJ, Ferrer JMR (1993) The incidence of bifurcation among corticocortical connections in the developing visual cortex of the cat. Eur J Neurosci 5:223-231.

Price DJ, Zumbroich TJ (1989) Postnatal devclopment of corticocortical efferents from area 17 in the cat's visual cortex. J Neurosci 9:600-613.

Price DJ, Caric D, Ferrer JMR (1992) The development and plasticity of corticocortical connections in the visual cortex. In: Development, transplantation and plasticity of the nervous system, Chap 14 (Nona $S$, ed). London: Chapman and Hall.

Price DJ, Ferrer JMR, Blakemore C, Kato N (1994) Functional organization of corticocortical projections from area 17 to area 18 in the cat's visual cortex. J Neurosci 14:2732-2746.

Salin PA, Bullier J, Kennedy H (1989) Convergence and divergence in the afferent projections to cat area 17. J Comp Neurol 283:486512.

Sengpiel F, Harrad R, Blakemore C (1992) Responses of cells in the cat's LGN and area 17 to rivalrous stimuli. Soc Neurosci Abstr 18: 295.

Shatz CJ, Luskin MB (1986) The relationship between the geniculocortical afferents and their cortical target cells during development of the cat's primary visual cortex. J Neurosci 6:3655-3668.

Stent GS (1973) A physiological mechanism for Hebb's postulate of learning. Proc Natl Acad Sci USA 70:997-1001.

Symonds LL, Rosenquist AC (1984) Corticocortical connections among visual areas in the cat. J Comp Neurol 229:1-38.

Tusa RJ, Palmer LA, Rosenquist AC (1978) The retinotopic organization of area 17 (striate cortex) in the cat. J Comp Neurol 177: 213-236.

Tusa RJ, Rosenquist AC, Palmer LA (1979) Retinotopic organization of areas 18 and 19 in the cat. J Comp Neurol 185:657-678.

Wong-Riley M (1979) Changes in the visual system of monocularly sutured or enucleated cats demonstrable with cytochrome oxidase histochemistry. Brain Res 171:11-28. 